\title{
Unilateral Capital Transfers, Public Investment, and Economic Growth
}

\author{
Santanu Chatterjee, Georgios Sakoulis, and Stephen J. Turnovsky ${ }^{\mathrm{a}, \mathrm{b}}$ \\ Department of Economics, University of Washington \\ Seattle, WA 98195-3330, USA
}

\begin{abstract}
This paper analyzes the impact of both permanent and temporary tied transfers on the growth and macroeconomic performance of a small recipient open economy. We show how there is a sharp contrast in the effects of traditional pure transfers and transfers tied to investment in public infrastructure such as adopted by the European Union in its Structural Funds and Pre-accession aid programs. A permanent pure transfer has no growth or dynamic consequences. It is always welfare-improving, the gains varying positively with the size of the government, when the stock of debt and the benefits of debt reduction increase. A tied transfer generates dynamic adjustments, as public capital is accumulated in the recipient economy. Its effect on the long-run growth rate, and the extent to which this is beneficial, depends upon the initial size of the infrastructure in the economy, as well as any co-financing arrangements. These contrasts also apply for temporary transfers, in particular on the transitional dynamics in the two cases. Whereas a temporary pure transfer has only modest short-run growth effects and leads to a permanent deterioration of the current account, a productive transfer has significant impacts on short-run growth, leading to permanent improvements in the levels of key economic variables including welfare and the current account, thus validating the position taken by the EU.
\end{abstract}

JEL Classification: E0, E6, F0

\footnotetext{
${ }^{\text {a } C h a t t e r j e e: ~ s a n t a n u @ u . w a s h i n g t o n . e d u, ~ S a k o u l i s: ~ g s a k o u l i @ u . w a s h i n g t o n . e d u, ~ T u r n o v s k y: ~}$ sturn@u.washington.edu

${ }^{\mathrm{b}}$ We would like to thank Charles Engel, Levis Kochin and participants at the International Macroeconomics Brown Bag Seminar Series at the University of Washington for helpful comments and suggestions.

This paper was completed while Chatterjee, Sakoulis and Turnovsky were visiting the University of California at Berkeley. The hospitality of the Departments of Economics and Agriculture and Resource Economics at UC, Berkeley is gratefully acknowledged. Chatterjee would like to thank the Castor Endowment for financial support. Sakoulis would like to thank the Castor Endowment and the James K. and Viola M. Hall Fellowship for financial support.
} 


\section{Introduction}

Investment in public infrastructure is widely recognized as being an essential component of economic development and growth. Services associated with the use of infrastructure account for roughly 7 to $9 \%$ of GDP in low and middle-income countries. Infrastructure in these countries typically represents about $20 \%$ of total investment and 40 to $60 \%$ of public investment. ${ }^{1} \quad$ The stock of physical infrastructure is thus an important input in the production process of such economies, raising the efficiency and productivity of the private sector, and thereby providing a crucial channel for growth, distribution of output, and ultimately higher living standards.

The issue of infrastructure has recently assumed a central role in the context of the expanding European Union. In several instances, the per capita level of GDP of joining members to the Union has been below the EU average. For example, in 1988, the per capita GDPs (in purchasing power parity) of Greece, Ireland and Portugal were only 54.4, 64.6, and 53.8\%, respectively, of the EU average. Moreover, these countries were also experiencing low growth rates that even exhibited tendencies to decline. As a consequence, the EU introduced pre-accession aid programs to assist these and other potential member nations in their transition into the union. This process of "catching up" began in 1989 with a program of unilateral capital transfers from the EU through its Structural Funds program, and subsequent programs were introduced in 1993 and in 2000. These assistance programs tied the capital transfers to the accumulation of public capital, aimed at building up the infrastructure of the recipient nation, and thereby enabling it to maintain a growth rate compatible with that of the European Union.

How the investment in infrastructure is to be financed is important. A significant source for the financing of investment in public infrastructure in resource-constrained developing economies is external financing. Such financing could be in the form of borrowing from abroad, or through unilateral capital transfers, as in case of the European

\footnotetext{
${ }^{1}$ World Bank (1994).
} 
Union. But at the same time, it is also likely that external assistance and borrowing will not meet the total financial needs for public investment, and hence domestic participation by both the government and the private sector is also important.

The objective of this paper is to analyze the process of developmental assistance in the form of tied-capital transfers to a small growing open economy. The model has the following key characteristics. First, the assistance is tied to the accumulation of public capital, which is therefore an important stimulus for private capital accumulation and growth. Second, we assume that public investment in infrastructure is financed both by the domestic government, as well as via the flow of international transfers, thereby incorporating the important element of domestic co-financing, characteristic of the European Union. The international transfers are assumed to be tied to the scale of the recipient economy and therefore are consistent with maintaining an equilibrium of sustained (endogenous) growth. The model is sufficiently general to include the possibility of a third source of financing public infrastructure, the private sector of the economy. By taxing private firms, and spending a fixed proportion of those taxes in financing new infrastructure, the government can ensure the private sector's participation in building up the economy's stock of infrastructure. ${ }^{2}$

We assume that the small open economy faces restricted access to the world capital market in the form of an upward-sloping supply curve of debt, according to which the country's cost of borrowing depends upon its debt position, relative to its capital stock, the latter serving as a measure of its debt-servicing capability. This assumption is motivated by the large debt burdens of most developing countries, which give rise to the potential risk of default on international borrowing. Indeed, evidence suggesting that more indebted economies pay a premium on their loans from international capital markets to insure against default risk has been provided by Edwards (1984).

\footnotetext{
${ }^{2}$ The efficient use of infrastructure is a further important issue. For example, Hulten (1996) shows that inefficient use of infrastructure accounts for more than 40 percent of the growth differential between high and low growth countries.
} 
Both theoretical and empirical interest in the impact of public capital on private capital accumulation and economic growth originated with the work of Aschauer (1989a, 1989b). ${ }^{3}$ Most of this literature has focused on closed economies, using both the Ramsey model and the AK endogenous growth framework; see e.g. Futagami, Morita, and Shibata (1993), Baxter and King (1993), Fisher and Turnovsky (1998). Turnovsky (1997a) extends Futagami et. al. to a small open economy and introduces various forms of distortionary taxation, as well as the possibility of both external and internal debt financing. Devarajan, Xie, and Zou (1998) address the issue of whether public capital should be provided through taxation or through granting subsidies to private providers.

The question we are addressing is closely related to the "transfer problem", one of the classic issues in international economics, dating back to Keynes (1929), Ohlin (1929), Pigou (1932) and Samuelson (1952, 1954). This early literature was concerned with "pure" transfers, which could be in the form of an unrestricted gift or as debt-relief. It suggested that in a two-country world with stable markets and no distortions, international transfers, through their effects on the terms of trade, impoverish the donor and enrich the recipient. But the incorporation of distortions or a third nation into the framework can lead to a reversal of these welfare effects. ${ }^{4}$ Recent research on the transfer problem has focused on further aspects of the welfare effects of international transfers. Turunen-Red and Woodland (1988) show that a Pareto improving multilateral transfer exists only in the presence of a tariff distortion. Haaparanta (1989) argues that the effects of transfers depend upon their mode of financing and disbursement, and may be different in the short run and the long run. Brock (1996) employs a dependent economy model and shows that a small economy's macroeconomic adjustment to a transfer depends upon the relative capital intensities of the traded and non-traded sectors.

By contrast, our analysis focuses on "productive" transfers, the use of which is tied to public investment. However, the formulation we develop parameterizes the

\footnotetext{
${ }^{3}$ See Gramlich (1994) for a comprehensive survey of the recent empirical literature.

${ }^{4}$ See for example, Bhagwati et. al. (1983, 1985), and Galor and Polemarchakis (1987).
} 
transfer so that we can conveniently identify the pure transfer and the productive transfer as polar cases. We embed the transfer in an intertemporal framework, thus enabling us to compare both the short-run and the long-run effects of the two types of transfers on the dynamic evolution and growth rate of the economy, and ultimately on welfare. Both permanent and temporary transfers are analyzed. Indeed, in light of the fact that typical transfer programs, such as those operated by the EU are only temporary, this latter case becomes particularly relevant.

Because of the complexity of the model, most of the analysis is conducted numerically. In general, the impact of a transfer on the economy depends crucially upon (i) whether or not it is "pure" or "tied" to public investment and (ii) how the government responds. The main results of our model include the following. A permanent pure transfer has no intertemporal effects; it simply raises current consumption instantaneously, raising welfare correspondingly. By contrast, a tied transfer generates a dynamic adjustment. But whether it benefits or harms the economy depends upon its initial stock of public capital. In the most relevant case, where the economy is underendowed with public capital, a tied transfer will raise the growth rate permanently and will raise welfare by a larger amount than if the transfer is pure. However, if the recipient economy is relatively well-endowed with public capital, a tied transfer may reduce the growth rate and be harmful. In that case, the economy can still be made better off with a pure transfer. In any event, the economy can always convert a tied transfer to a pure transfer, by a corresponding reduction in its own participation. Furthermore, we show how the government can maximize the benefits of the tied transfer by the appropriate coordinated determination of its expenditure and tax rates. On the other hand, we show that if it responds by choosing its policy instruments to maximize the growth rate, it can be made worse off by the tied transfer. There is thus a sharp tradeoff between welfare-maximization and growth-maximization, not present in the Barro (1990) model, but characteristic of the Futagami et. al. (1993) model. 
Both a temporary pure transfer and a temporary productive transfer generate transitional dynamics, though of a sharply contrasting nature. Temporary pure transfers have only modest short-run growth effects, which impact most directly on private capital, causing the dynamics, as represented by the public-private capital and debt-private capital ratios, to decline in the short run. These adjustments are then reversed after the temporary pure transfer ceases and the economy reverts back to its original equilibrium. The tied transfer, has much more potent short-run growth effects, and by impinging more directly on public capital and debt, yields precisely the opposite transitional dynamics. The public-private capital and debt-capital ratios now increase in the short run, and decline after the removal of the shock. By influencing the transitional growth rates, temporary transfers have permanent effects on the levels of key variables such as the capital stocks, output, and welfare, these gains being more significant for the productive transfer. One striking contrast between the two transfers is that the productive transfer leads to a decline in the long-run debt of the recipient economy, whereas the pure transfer leads to greater long-run indebtedness.

The rest of the paper is organized as follows. Section 2 motivates the model by discussing recent developments in the European Union to the context of financing investment in public infrastructure through unilateral capital transfers in its less developed member nations, as well as to aspiring members. Section 3 outlines the model and its chief characteristics. Section 4 briefly discusses the long-run effects of transfers and related fiscal shocks, while Section 5 discusses two forms of government response. Section 6 provides a numerical examination of the transitional paths in response to permanent transfers, while temporary transfers are addressed in Section 7. Section 8 presents the concluding remarks and some technical details are relegated to the Appendix. 


\section{Financing Investment in Infrastructure by Capital Transfers: The Case of the European Union}

The role of investment in infrastructure has assumed increased importance, especially in the context of the European Union's pre-accession aid programs. The motivation behind these programs is the realization that there are wide and persistent disparities in economic conditions among the EU countries and its aspiring members. One of the critical reasons for low growth rates and living standards in the less developed countries within the EU, as well as its aspiring members, is the deterioration and inadequacy of physical infrastructure in certain key sectors. To raise the economic conditions in the less developed regions to EU standards, strong positive differentials in growth rates needed to be created in favor of these economies, relative to the EU average, in the short run. Identifying inadequate infrastructure as the key bottleneck in the growth process, in 1989 the EU embarked on an ambitious program of assisting its less developed members in building up an adequate and efficient stock of infrastructure, and thereby enhancing their growth rates. This process of "catching up" started in 1989 with a program of unilateral capital transfers from the EU through its Structural Funds program: the European Agriculture Guidance and Guarantees Fund (EAGGF, Guidance section), the European Regional Development Fund (ERDF), the European Social Fund (ESF), and, after 1993, through the Cohesion Fund. Country-specific targets and priorities were decided by the EU on the basis of the Community Support Framework (CSF) for each country, and financial support through these structural funds have been increasing over the years. A key aspect of these transfer programs was co-financing: national governments and the private sector had to contribute with matching funds in given proportions to the funds provided by the EU. Under the additionality principle, measures were taken to prevent the recipient economies from decreasing their own financial commitments in the various target areas. Specifically, these transfers were aimed at (i) infrastructure improvement projects in key sectors, (ii) improvements in the quality of human capital, and (iii) structural interventions in key areas. The ultimate 
objective under the CSF plans was to correct the structural deficiencies in capital formation and infrastructure, and push these economies onto a path of sustainable growth. For example, EU support under CSF I (1989-1993) to Greece, Ireland, Portugal and Spain amounted to 4.5, 6, 6.1 and $1.6 \%$, respectively, of their annual GDPs. During this period, Ireland achieved an average GDP growth rate of 5\%, while Portugal and Spain had 2.8 and $2 \%$ respectively, and Greece was least successful with $1.2 \%$. Under CSF II (1994-1999), transfers were almost doubled for these countries, with assistance of $7.2 \%$ of GDP for Greece, 7.1\% of GDP for Portugal, 3.4\% for Spain and 5\% for Ireland. Ireland is expected to achieve an average growth rate of $8.9 \%$ during this period, while the corresponding estimates for Spain and Portugal are 2.9\% and 2.6\% for Greece.

Encouraged by the success of the above mentioned capital transfer program, the EU has embarked on a new transfer program, called Agenda 2000, to assist aspiring members to the EU in gaining accession to the Union. Agenda 2000 outlines a coherent strategy for all Central and Eastern European applicant countries (CEECs) to gain accession to the EU through unilateral transfers similar to that of the CSF structural funds program. Under this transfer program, recipient countries will be entitled to Euro 1 billion per year for the period 2000-2006. ${ }^{5}$ This aid would be directed mainly toward aligning the applicant countries on community infrastructure standards, particularly in the transport and environmental spheres. Following the objectives of the Cohesion Fund, the EU has proposed an Instrument for Structural Policies for Pre-Accession (ISPA) package under Agenda 2000 to assist the CEECs in gaining membership to the Union. Considering the size of these countries, the proposed assistance through transfers will be large. For example, the earmarked assistance for the environment sector alone (particularly water and air pollution and waste management) is estimated to be Euro 1000 per capita of the ten applicant countries. Combined with the transfers to the transport and other infrastructure sectors, the total transfers are estimated to be between $4-6 \%$ of the

\footnotetext{
${ }^{5}$ The recipient countries include Bulgaria, the Czech Republic, Estonia, Hungary, Latvia, Lithuania, Poland, Romania, Slovakia and Slovenia.
} 
recipient country's GDP. The aim here is also to help these countries correct their infrastructural deficiencies, attain strong positive growth differentials relative to the $\mathrm{EU}$ average in the short run, and achieve higher and sustainable standards of living in alignment with EU standards, and ultimately, gain accession to EU membership. To analyze the effects of these unilateral transfer programs provides the main motivation for this paper.

\section{The Analytical Framework}

\subsection{Private Sector}

We consider a small open economy populated by an infinitely-lived representative agent who produces and consumes a single traded commodity. Output, $Y$, of the commodity is produced using the constant returns to scale production function

$$
Y=\alpha\left(\frac{K_{G}}{K}\right)^{\eta} K=\alpha K_{G}^{\eta} K^{1-\eta} ; \alpha>0,0<\eta<1
$$

where $K$ denotes the representative agent's stock of private capital and $K_{G}$ denotes the stock of public capital. Equation (1a) assumes that the services of public capital enhance the productivity of private capital, though at a diminishing rate. The model abstracts from labor so that private capital should be interpreted broadly to include human, as well as physical capital; see Rebelo (1991).

The agent consumes this good at the rate $C$, yielding utility over an infinite horizon represented by the isoelastic utility function: ${ }^{6}$

$$
U \equiv \int_{0}^{\infty} \frac{1}{\gamma} C^{\gamma} e^{-\beta t} d t ; \quad-\infty<\gamma<1
$$

The agent also accumulates physical capital, with expenditure on a given change in the capital stock, $I$, involving adjustment (installation) costs specified by the quadratic (convex) function

\footnotetext{
${ }^{6}$ The exponent $\gamma$ is related to the intertemporal elasticity of substitution $s$, by $s=1 /(1-\gamma)$, with $\gamma=0$ being equivalent to a logarithmic utility function.
} 


$$
\Psi(I, K)=I+h_{1} \frac{I^{2}}{2 K}=I\left(1+\frac{h_{1}}{2} \frac{I}{K}\right)
$$

This equation is an application of the familiar cost of adjustment framework, where we assume that the adjustment costs are proportional to the rate of investment per unit of installed capital (rather than its level). The linear homogeneity of this function is necessary for a steady-state equilibrium having ongoing growth to be sustained. The net rate of capital accumulation is thus:

$$
\dot{K}=I-\delta_{K} K
$$

where $\delta_{K}$ denotes the rate of depreciation of private capital.

Agents may borrow internationally on a world capital market. The key factor we wish to take into account is that the creditworthiness of the economy influences its cost of borrowing from abroad. Essentially we assume that world capital markets assess an economy's ability to service debt costs and the associated default risk, the key indicator of which is the country's debt-capital (equity) ratio. As a result, the interest rate countries are charged on world capital markets increases with this ratio. This leads to the upward sloping supply schedule for debt, expressed by assuming that the borrowing rate, $r(N / K)$, charged on (national) foreign debt, $N$, is of the form:

$$
r(N / K)=r^{*}+\omega(N / K) ; \quad \omega^{\prime}>0
$$

where $r^{*}$ is the exogenously given world interest rate and $\omega(N / K)$ is the country-specific borrowing premium that increases with the nation's debt-capital ratio. The homogeneity of the relationship is required to sustain a balanced growth equilibrium. ${ }^{7}$ Various formulations can be found in the literature. The original formulation by Bardhan (1967)

\footnotetext{
${ }^{7}$ A rigorous derivation of (1e) presumes the existence of risk. Since we do not wish to model a full stochastic economy, we should view (1e) as representing a convenient reduced form, one supported by empirical evidence; see e.g. Edwards (1984) who finds a significant positive relationship between the spread over LIBOR (e.g. $r^{*}$ ) and the debt-GNP ratio. Eaton and Gersovitz (1989) provide formal justifications for the relationship (1e).
} 
expressed the borrowing premium in terms of the absolute stock of debt. ${ }^{8}$ But authors such as Sachs (1984) and Cooper and Sachs (1985) also argue for a homogeneous function such as (1e). They suggest how a country, by adopting growth-oriented policies, can shift the upward-sloping supply curve outward, so that at each level of debt a lower borrowing premium is charged. This effect can be incorporated by assuming that the borrowing premium depends upon the level of debt relative to some measure of earning and debt-servicing capacity, such as capital or output (that depends upon capital), as formulated in $(1 \mathrm{e})^{9}$

The agent's decision problem is to choose consumption, and the rates of accumulation of capital and debt, to maximize intertemporal utility (1b) subject to the flow budget constraint

$$
\dot{B}=C+r(N / K) B+\Psi(I, K)-(1-\tau) Y+\bar{T}
$$

where $B$ is the stock of debt held by the private sector, $\tau$ is the income tax rate, and $\bar{T}$ denotes lump-sum taxes. ${ }^{10}$ It is important to emphasize that in performing his optimization, the representative agent takes the borrowing rate, $r($.$) as given. This is$ because the interest rate facing the debtor nation, as reflected in its upward sloping supply curve of debt, is a function of the economy's aggregate debt-capital ratio, which the individual agent assumes he is unable to influence.

The optimality conditions with respect to $C$ and $I$ are respectively

$$
\begin{aligned}
& C^{\gamma-1}=v \\
& 1+h_{1}(I / K)=q
\end{aligned}
$$

\footnotetext{
${ }^{8}$ See also Obstfeld (1982) and Bhandari, Haque, and Turnovsky (1990).

${ }^{9}$ See also van der Ploeg (1996).

${ }^{10}$ It is natural for us to assume $B>0$, so that the country is a debtor nation. However, it is possible for $B<$ $O$ in which case the agent accumulates credit by lending abroad. For simplicity, interest income is assumed to be untaxed.
} 
where $v$ is the shadow value of wealth in the form of internationally traded bonds , $q$ ' is the shadow value of the agent's private capital stock, and $\quad v$ is defined as the market price of private capital in terms of the (unitary) price of foreign bonds. The first of these conditions equates the marginal utility of consumption to the shadow value of wealth, while the latter equates the marginal cost of an additional unit of investment, which is inclusive of the marginal installation cost $h_{1} I / K$, to the market value of capital. Equation (3b) may be immediately solved to yield the following expression for the rate of private capital accumulation

$$
\frac{\dot{K}}{K} \equiv \phi_{K}=\frac{q-1}{h_{1}}-\delta_{K}
$$

Applying the standard optimality conditions with respect to $B$ and $K$ implies the standard arbitrage relationships

$$
\begin{gathered}
\beta-\frac{v}{v}=r\left(\frac{N}{K}\right) \\
\frac{(1-\tau)(1-\eta) \alpha K_{G}^{\eta} K^{-\eta}}{q}+\frac{\dot{q}}{q}+\frac{(q-1)^{2}}{2 h_{1} q}-\delta_{K}=r\left(\frac{N}{K}\right)
\end{gathered}
$$

Equation (4a) is the standard Keynes-Ramsey consumption rule, equating the rate of return on consumption to the cost of incurring an additional unit of foreign debt. Likewise, (4b) equates the after-tax rate of return on domestic capital to the cost of debt. The gross return on private capital (left hand side of (4b)) has three components: the first is the after-tax marginal productivity of private capital valued at its market price. The second component is the rate of change in the price of capital. The third element reflects the fact that an additional source of benefits of a higher capital stock is to reduce the installation costs (which depend upon $I / K$ ) associated with new investment.

Finally, in order to ensure that the agent's intertemporal budget constraint is met, the following transversality conditions must hold: 


$$
\lim _{t \rightarrow \infty} v B e^{-\beta t}=0 ; \quad \lim _{t \rightarrow \infty} q^{\prime} K e^{-\beta t}=0
$$

\subsection{Public Capital, Fiscal Transfers, and National Debt}

We assume that the gross accumulation of public capital, $G$, is also subject to convex costs of adjustment, similar to that of private capital

$$
\Omega\left(G, K_{G}\right)=G\left(1+\left(h_{2} / 2\right)\left(G / K_{G}\right)\right)
$$

In addition, the stock of public capital depreciates at the rate $\delta_{G}$ so that the net rate of public capital accumulation is,

$$
\dot{K}_{G}=G-\delta_{G} K_{G}
$$

The resources for accumulation of public capital come from two sources: domestically financed government expenditure on public capital, $\bar{G}$, and a program of fiscal transfers, $T R$, from the rest of the world. We therefore postulate

$$
G \equiv \bar{G}+\lambda T R \quad 0 \leq \lambda \leq 1
$$

where $\lambda$ represents the degree to which the flow of transfers from abroad is tied to investment in the stock of public infrastructure. The case $\lambda=1$ implies that transfers are completely tied to investment in public capital, representing a "productive" transfer. The other polar case, $\lambda=0$, implies that incoming transfers are not invested in public capital and hence represents a "pure" transfer, of the Keynes-Ohlin type. In order to sustain an equilibrium of on-going growth, both domestic government expenditure on infrastructure $(\bar{G})$ and the flow of transfers from abroad must be tied to the scale of the economy

$$
\bar{G}=\bar{g} Y, \text { and } T R=\sigma Y, \quad 0<\bar{g}<1, \sigma>0, \quad 0<\bar{g}+\sigma<1
$$

We can therefore rewrite (5) in the following form

$$
\dot{K}_{G}=G-\delta_{G} K_{G}=g Y-\delta_{G} K_{G}=(\bar{g}+\lambda \sigma) Y-\delta_{G} K_{G} ; g=\bar{g}+\lambda \sigma>0
$$


and dividing (5) by $K_{G}$, the growth rate of public capital is given by

$$
\frac{\dot{K}_{G}}{K_{G}} \equiv \phi_{G}=(\bar{g}+\lambda \sigma) \frac{Y}{K_{G}}-\delta_{G} .
$$

The government faces the flow budget constraint

$$
\dot{A}=\Omega\left(G, K_{G}\right)+r(N / K) A-\tau Y-T R-\bar{T}
$$

This equation states that the excess of domestic government expenditure on public infrastructure and interest payments on debt over tax and transfer receipts, is financed by accumulating debt $(A)$. Note that if $\lambda=0$, the transfer results in an equivalent reduction in government debt. If $\lambda=1$ a unit increase in transfers raises the flow of government purchases correspondingly. In the absence of installation costs $\left(h_{2}=0\right)$ this will leave the stock of government debt unchanged. But to the extent that public investment involves installation costs, which require domestic resources, a unit increase in transfers will actually require the government to issue additional debt to finance the installation component of the investment. In addition we require that the government satisfy its intertemporal budget constraint specified as:

$$
\lim _{t \rightarrow \infty} A e^{-r(.) t}=0
$$

National debt is the sum of private debt and public debt, $N=B+A$. Thus combining (7) and (2) we get the national budget constraint (the nation's current account)

$$
\dot{N}=r(N / K) N+C+\Psi(I, K)+\Omega\left(G, K_{G}\right)-Y-T R .
$$

Equation (8) states that the economy accumulates debt to finance its expenditures on public capital, private capital, consumption and interest payments net of output produced and transfers received. It is immediately apparent that higher consumption or investment raises the rate at which the economy accumulates debt. On the other hand, higher transfers affect the growth rate of debt in two offsetting ways. The direct effect of higher 
transfers is to reduce the growth rate of debt (through the term $G-T R \equiv(1-\lambda) \sigma Y)$. But the installation costs of infrastructure (the term $\left.\left(h_{2} / 2\right) G^{2} / K_{G}\right)$ increase the total expenditure on providing infrastructure, and thereby tend to increase the growth rate of debt relative to private capital. This is the indirect effect of higher transfers. An interesting observation is that the higher is the degree to which transfers are tied to public investment (higher $\lambda$ ), the lower will be the decrease in the growth rate of debt. When, transfers are completely tied to investment in infrastructure, i.e., $\lambda=1$, there is no direct effect on the growth of debt. However, the indirect effects, through changes in installation costs, market price of private capital $(q)$, and consumption, will still continue to affect the growth rate of debt.

\subsection{Macroeconomic Equilibrium}

The steady-state equilibrium we shall derive has the characteristic that all real quantities grow at the same constant rate and that $q$ the relative price of capital is constant. Thus we shall express the core dynamics of the system in terms of the following stationary variables, normalized by the stock of private capital, $c \equiv C / K, k_{g} \equiv K_{G} / K, n \equiv N / K$, and $q$. The equilibrium system is derived as follows.

First, taking the time derivative of $k_{g}$ and substituting (5") and (3b') yields

$$
\frac{\dot{k_{g}}}{k_{g}} \equiv \phi_{G}-\phi_{K}=(\bar{g}+\lambda \sigma) \alpha k_{g}^{\eta-1}-\frac{(q-1)}{h}-\left(\delta_{G}-\delta_{K}\right)
$$

Next, dividing (8) by $N$, and substituting, we can rewrite (8) as

$$
\frac{\dot{N}}{N} \equiv \phi_{N}=r(n)+\frac{1}{n}\left[\{(\bar{g}+\lambda \sigma)-(1+\sigma)\} \alpha k_{g}^{\eta}+\alpha^{2} \frac{h_{2}}{2}(\bar{g}+\lambda \sigma)^{2} k_{g}^{2 \eta-1}+\frac{\left(q^{2}-1\right)}{2 h}+c\right]
$$

Taking the time derivative of $n$ and combining with (3b') leads to:

$$
\frac{\dot{n}}{n} \equiv \phi_{N}-\phi_{K}=r(n)+\frac{1}{n}\left[\{(\bar{g}+\lambda \sigma)-(1+\sigma)\} \alpha k_{g}^{\eta}+\alpha \frac{h_{2}}{2}(\bar{g}+\lambda \sigma)^{2} k_{g}^{2 \eta-1}+\frac{\left(q^{2}-1\right)}{2 h}+c\right]
$$




$$
-\left(\frac{q-1}{h}\right)+\delta_{K}
$$

Third, from (3a) and (4a), we derive the growth rate of consumption

$$
\frac{\dot{C}}{C} \equiv \phi_{C}=\frac{r(n)-\beta}{1-\gamma}
$$

Taking the time derivative of $c$ and combining with (3b') leads to:

$$
\frac{\dot{c}}{c} \equiv \phi_{C}-\phi_{K}=\frac{r(n)-\beta}{1-\gamma}-\frac{(q-1)}{h}+\delta_{K}
$$

Finally, rewriting (4b) implies

$$
\dot{q}=r(n) q-(1-\tau)(1-\eta) \alpha k_{g}^{\eta}-\frac{(q-1)^{2}}{2 h}+\delta_{K} q
$$

Equations (9a) - (9d) provide an autonomous set of dynamic equations in $k_{g}, n, c$, and $q$, from which the evolution of government debt can be derived.

\subsection{Steady State Equilibrium}

The economy reaches steady state when $\dot{k}_{g}=\dot{n}=\dot{c}=\dot{q}=0$, implying that $\dot{K} / K=\dot{K}_{G} / K_{G}=\dot{N} / N=\dot{C} / C \equiv \tilde{\phi}$, the steady-state growth rate of the economy. The steady state can thus be described as follows:

$$
\begin{gathered}
(\bar{g}+\lambda \sigma) \alpha k_{g}^{\eta-1}-\delta_{G}=\frac{\tilde{q}-1}{h_{1}}-\delta_{K} \\
r(\tilde{n})-\frac{1}{\tilde{n}}\left\lfloor\{1-\bar{g}+(1-\lambda) \sigma\} \alpha \tilde{k}_{g}^{\eta}-\alpha \frac{h_{2}}{2}(\bar{g}+\lambda \sigma)^{2} k_{g}^{2 \eta-1}-\frac{\left(\tilde{q}^{2}-1\right)}{2 h_{1}}-\tilde{c}\right\rfloor=\left(\frac{\tilde{q}-1}{h_{1}}\right)-\delta_{K} \\
r(\tilde{n}) \tilde{q}-(1-\tau)(1-\eta) \alpha \tilde{k}_{g}^{\eta}-\frac{(\tilde{q}-1)^{2}}{2 h_{1}}+\delta_{K} \tilde{q}=0 \\
\frac{r(\tilde{n})-\beta}{1-\gamma}=\frac{(\tilde{q}-1)}{h_{1}}-\delta_{K}=\tilde{\phi}
\end{gathered}
$$


Equations (10a)-(10d) determine the steady-state equilibrium in the following recursive manner. First, equations (10a), (10c) and (10d) jointly determine $k_{g}, \tilde{q}$, and $r(\tilde{n})$, from which the steady state growth rate $\phi$ immediately follows. These quantities are independent of (i) the adjustment cost of public capital, $h_{2}$, and (ii) the sensitivity of the country-specific borrowing cost, as reflected by $r^{\prime}(\tilde{n})$. Having determined $\tilde{r}$, the equilibrium stock of debt-capital ratio, $n$, is obtained from (1e). In particular, a higher interest sensitivity of borrowing costs lowers the equilibrium stock of debt. Given $k_{g}, \tilde{q}, r(\tilde{n})$, and $\tilde{n}$, the equilibrium consumption-capital ratio, $\tilde{c}$, is obtained from the current account equilibrium condition (10b). Provided $\tilde{r}>\tilde{\phi}$ (which we shall show below is required for the transversality condition to hold) higher marginal borrowing costs reduce total interest payments raising the consumption-capital ratio. Also, higher installation costs, $h_{2}$, reduce the amount of output available for consumption, $c$.

Because this system is highly non-linear, it need not be consistent with a welldefined steady state equilibrium with $k_{g}>0, \tilde{c}>0$. Our numerical simulations, however, yield well-defined steady state values for all plausible specifications of all the structural and policy parameters of the model. ${ }^{11}$

\subsection{Equilibrium Dynamics}

Equations (9a) - (9d) form the dynamics of the system in terms of $k, n, q$, and $c$. Linearizing these equations around the steady-state values of $k_{g}, n, q$, and $c$ obtained from $(10 a)-(10 d)$,

$$
\left(\begin{array}{c}
\dot{k_{g}} \\
\dot{n} \\
\dot{c} \\
\dot{q}
\end{array}\right)=\left(\begin{array}{cccc}
\eta \alpha(\bar{g}+\lambda \sigma) \tilde{k}_{g}^{\eta-1}-\delta_{G}-\tilde{\phi} & 0 & 0 & -\left(\tilde{k}_{g} / h_{1}\right) \\
a_{21} & r^{\prime}(\tilde{n}) \tilde{n}+r(\tilde{n})-\tilde{\phi} & 1 & \left(1 / h_{1}\right)(\tilde{q}-\tilde{n}) \\
0 & r^{\prime}(\tilde{n}) \tilde{c} /(1-\gamma) & 0 & -\left(\tilde{c} / h_{1}\right) \\
-\eta \alpha(1-\tau)(1-\eta) \tilde{k}_{g}^{\eta-1} & r^{\prime}(\tilde{n}) \tilde{q} & 0 & r(\tilde{n})-\tilde{\phi}
\end{array}\right)\left(\begin{array}{c}
k_{g}-\tilde{k}_{g} \\
n-\tilde{n} \\
c-\tilde{c} \\
q-\tilde{q}
\end{array}\right)
$$

where

\footnotetext{
${ }^{11}$ A rigorous discussion of the issues giving rise to non-existent or multiple equilibria in a related model is provided by Turnovsky (1997a). Similar issues apply here.
} 


$$
a_{21} \equiv-\eta\left\{1-\bar{g}+(1-\lambda) \sigma \tilde{k}_{g}^{\eta-1}\right\}+(2 \eta-1) \alpha^{2}\left(h_{2} / 2\right)(\bar{g}+\lambda \sigma)^{2} k_{g}^{2 \eta-2}
$$

The determinant of the coefficient matrix of (11) is positive under the condition that $r(\tilde{n})>\tilde{\phi}$ i.e., the steady-state interest rate facing the small open economy must be greater than the steady-state growth rate of the economy. ${ }^{12}$ Imposing the transversality condition (4c), we see that this condition is indeed satisfied. Since (11) form a fourth-order system, a positive determinant implies that there could be 0,2 , or 4 positive (unstable) roots and correspondingly 4,2 , or 0 negative(stable) roots. Imposing the following sufficiency conditions: (i) $-1 / 2<\gamma<0$, (ii) $\delta_{G} \leq \delta_{K}$ and (iii) $\tilde{q}>\tilde{n}$, we are able to rule out the case of 0 and 4 positive roots. ${ }^{13}$ Conditions (i) and (ii) impose restrictions on the structural parameters $\gamma, \delta_{K}$ and $\delta_{G}$ and (iii) states that in steady-state, the value of the capital stock in the economy must be greater than the value of its outstanding stock of debt. Under these conditions the dynamic system (11) can be shown to be saddle-point stable with two positive (unstable) and two negative (stable) roots. We denote the two stable roots by $\mu_{1}$ and $\mu_{2}$, with $\mu_{2}<\mu_{1}<0$.

\section{Long-run Effects of Transfers and Fiscal Shocks}

Table 1A summarizes the long-run effects of a permanent transfer on the key equilibrium variables, including the public to private capital ratio. These results imply that a permanent transfer tied to public capital will raise the long-run ratio of public to private capital. This increases the productivity of private capital, thereby raising its

\footnotetext{
${ }^{12}$ The determinant of the coefficient matrix in (11) is given by $\frac{(1-\eta)(\tilde{q}-1) r^{\prime}(\tilde{n})}{h}\left[\frac{\tilde{c} \tilde{q}}{h}+\frac{\tilde{c}}{1-\gamma}\left\{r(\tilde{n})-\frac{\tilde{q}-1}{h}+\delta_{K}\right\}\right]+\frac{\tilde{k_{g}} r^{\prime}(\tilde{n})}{h} \frac{\tilde{c}}{1-\gamma} \eta(1-\tau)(1-\eta) \alpha \tilde{k}_{g}^{\eta-1}>0$ if $r(\tilde{n})>\tilde{\phi}$.

${ }^{13}$ Let $\mu$ be the vector of characteristic roots of the system in (11). Then, the characteristic equation is a fourth-order polynomial of the form $\mu^{4}+\pi_{1} \mu^{3}+\pi_{2} \mu^{2}+\pi_{3} \mu+\pi_{4}=0$, where $\pi_{i}(i=1,2,3,4)$ are functions of the terms in the coefficient matrix in (11). By the determinental condition, $\pi_{4}>0$. Imposing (i) $-1 / 2<\gamma<0$, and (ii) $\delta_{G}<\delta_{K}$ we see that $\pi_{1}>0$. Condition (ii) $q>\tilde{n}$, leads to $\pi_{2}<0$. Then, by applying Descartes rule of signs, we can show that there are a maximum of two positive roots. Also, condition (i) implies that the trace of the matrix in (11) is positive, which rules out the case of 0 positive roots. Hence the system has two positive roots and two negative roots. Note that conditions (i)-(iii) are only sufficient conditions for saddle-point stability. Other more complex conditions can also be derived for this purpose. Numerical solutions to the steady state do not require the imposition of these conditions.
} 
relative price and the equilibrium growth rate. Financing the higher investment expenditures for the accumulation of private capital increases the agents' holdings of debt and thus increases the steady-state stock of national debt relative to private capital. The resulting effect (not reported) on the steady-state stock of consumption relative to private capital is ambiguous. We can show that the effect on consumption is a weighted average of two terms, the weights being $\lambda$ and $(1-\lambda)$. The first is applied to two components, one representing the effect of a higher ratio of public to private capital, the other the increase in the market price of private capital. A higher stock of public relative to private capital raises output relative to private capital and therefore tends to increase consumption relative to private capital. On the other hand, higher investment in public capital increases its installation costs and this leads to a crowding out of private consumption. Moreover, the increase in the market price of private capital, and the consequent increase in private investment, makes the agent substitute away from consumption and this tends to reduce steady-state consumption. Depending on which component dominates, this first effect on consumption (which is proportional to $\lambda$ ) could either go up or down. The second term represents the effect of that part of transfers not tied to public investment, and hence is scaled by $(1-\lambda)$. Since a fraction $(1-\lambda)$ of resources are freed up with the inflow of higher transfers, they contribute toward increasing consumption. The overall effect on consumption is thus ambiguous.

Two critical factors in determining these long-run responses are (i) $\lambda$, the degree to which transfers are tied to investment in public infrastructure, and (ii) $r^{\prime}(n)$ the extent to which borrowing costs are tied to the nation's debt position. In the extreme case of a pure transfer $(\lambda=0)$ there is no effect on either the steady-state public-private capital ratio, the growth rate, or the nation's debt-capital ratio. All that happens is that the consumption-capital ratio increases. Furthermore, this adjustment occurs instantaneously and raises welfare unambiguously. In the limiting case where $r^{\prime}(n)=0$, the growth rates of the production side and consumption diverge to different rates; see Turnovsky (1997a). 
The (common) growth rate of public and private capital is enhanced by productive transfers, while the growth rate of consumption remains unaffected.

In Table 1B we see that the effects of an increase in the domestic rate of

participation, $\bar{g}$ on $\tilde{k}_{g}, \tilde{\phi}, \tilde{n}$ are identical to those of a productive transfer. Thus to the extent that the domestic government matches the tied transfer, the effects are reinforcing. Table 1C describes the effects of a higher distortionary tax rate. By having a contractionary effect on private capital accumulation, this also raises the ratio of public to private capital, while reducing the equilibrium growth rate and therefore the equilibrium interest rate, and thus the equilibrium debt to capital ratio.

\section{Optimal Responses}

As our numerical results will show, the effect of the capital transfer on the domestic economy depends in part upon the corresponding response (if any) of the domestic government. In this respect we see that a tied or "productive" fiscal transfer of a given amount, coupled with an equivalent decrease in government expenditure, is equivalent to an untied transfer of an equivalent amount. Here, we briefly discuss two other responses: (i) the growth-maximizing fiscal response, and (ii) the welfaremaximizing fiscal response.

\subsection{Growth-Maximizing Fiscal Response}

Suppose that the government sets its expenditure rate, $\bar{g}$, and its tax rate, $\tau$, so as to balance the costs of the net purchase of capital, given the transfers, namely

$$
\tau=\bar{g}-(1-\lambda) \sigma
$$

Installation costs are thus financed by issuing new debt or by lump-sum taxes in accordance with the flow constraint (7): 


$$
\dot{A}+\bar{T}=r(.) A+\left(h_{2} / 2\right)\left(G^{2} / K_{G}\right)
$$

Using (12), together with the results from Table 1A and 1B we can then establish that the steady-state growth rate will be maximized if $\bar{g}, \tau$ are set in accordance with

$$
\hat{\bar{g}}=\eta-\sigma(\lambda-\eta) ; \quad \hat{\tau}=\eta-\sigma(1-\eta)
$$

In the absence of foreign transfers, (13) reduces to the growth maximizing tax (=expenditure) rate $\hat{\tau}=\hat{\bar{g}}=\eta$, obtained originally by Barro (1990) in his flow model, and later by Futagami et. al. (1993) in their stock model. But the presence of foreign transfers $(\sigma>0)$ leads to a divergence between the growth-maximizing tax and expenditure rates, except in the case where the transfers are fully tied to investment in public capital. Both also deviate from $\eta$, in contrast to Barro (1990) and Futagami, et. al. (1993). Having the fraction, $\sigma$, of income coming from abroad, permits the tax rate to be lowered, so that $\hat{\tau} \leq \eta$. To the extent that the transfers are untied, $\bar{g}$ must exceed $\tau$, and in fact it will exceed $\eta$ if $\lambda<\eta$.

Substituting (13) into the dynamic system (9a) - (9d) we see that the equilibrium dynamics, including the steady-state, are independent of $\lambda$. In other words, if the government sets its expenditure and tax rates to maximize the growth rate, the transitional dynamics and the long-run equilibrium are rendered independent of the extent to which the transfers are tied to investment.

\subsection{Welfare-Maximizing Fiscal Response}

A second response is to determine constant fiscal responses, constrained by (12) that maximize the welfare gains generated by the transfer, namely

$$
\Delta(W)=\int_{0}^{\infty} \frac{1}{\gamma}\left[(C(t))^{\gamma}-(\tilde{C}(t))^{\gamma}\right]^{-\beta t} d t
$$

where $\tilde{C}$ is the consumption along an initial equilibrium balanced growth path. Evaluating this quantity numerically, we find that the welfare-maximizing choices of 
$\tau, \bar{g}$, subject to (12) are less than the growth-maximizing values, as in Futagami et. al. (1993) and Turnovsky (1997c). Moreover, setting $\tau, \bar{g}$ in this way, we again find that the equilibrium path (9a) $-(9 d)$ is independent of $\lambda$. This is an important result, since it implies that by combining the transfer with the appropriate expenditure and tax mix, the recipient economy can choose its equilibrium path and associated level of welfare, which is independent of any constraints imposed by the donor country.

\section{Numerical Analysis of Transitional Paths}

Further insights into the effects of transfers are obtained by analyzing the model numerically. We begin by calibrating a benchmark economy, using the following parameters representative of a small open economy, which starts out from an equilibrium with zero transfers.

Table 2. The Benchmark Economy

\begin{tabular}{|ll|}
\hline Preference parameters: & $\gamma=-1.5, \beta=0.04$ \\
Production parameters: & $\alpha=0.4, \eta=0.2, h_{1}=15, h_{2}=15$. \\
Depreciation rates: & $\delta_{K}=0.05, \delta_{G}=0.04$ \\
World interest rate: & $\bar{r}=0.06$, \\
Premium on borrowing: & $a=0.1^{14}$ \\
Policy parameters: & $\tau=0.15, g=0.05$ \\
Transfers: & $\sigma=0, \lambda=0$ \\
\hline
\end{tabular}

These parameter values are conventional and lead to the following plausible benchmark equilibrium reported in Row 1 of Table 3: the ratio of public-private capital is 0.29 ; the consumption-output ratio is 0.6 ; the debt to output ratio is 0.45 , leading to an equilibrium borrowing premium of $1.4 \%$ over the world rate; the capital-output ratio is over 3 , with

\footnotetext{
${ }^{14}$ The functional specification of the upward sloping supply curve that we use is: $r(n)=\bar{r}+e^{a n}-1$. Thus, in the case of a perfect world capital market, when $a=0, r=\bar{r}$, the world interest rate.
} 
the equilibrium growth rate being just under $1.4 \% .^{15}$ This equilibrium is a reasonable characterization of a small medium-indebted economy experiencing a modest steady rate of growth and having a relatively small stock of public capital. Rows $2-7$ summarize key short-run and long-run changes to this equilibrium following the specified changes. The final column in the table summarizes the effects on economic welfare, measured by the optimized utility of the representative agent

$$
W=\int_{0}^{\infty} \frac{1}{\gamma} C^{\gamma} e^{-\beta t} d t
$$

where $C$ is evaluated along the equilibrium path. These welfare changes are calculated as the percentage change in the initial stock of capital necessary to maintain the level of welfare unchanged following the particular shock.

\subsection{Permanent Shocks}

Row 2 reports the effects of a permanent pure transfer equal to $5 \%$ of the recipient country's GDP. This represents a pure wealth effect, which from (10a) - (10d) has no effect on $k_{g}, r(\tilde{n}), \tilde{n}, \tilde{\phi}$, and therefore no effect on the transitional adjustments. All that happens is that the transfer leads to an immediate and permanent increase in consumption, raising the consumption-output ratio from 0.60 to 0.65 , and leading to an increase in welfare of $8.3 \%$.

Row 3 describes the impact of a permanent productive transfer, fully tied to investment in public capital, and which is also 5\% of the economy's GDP. In the new steady state the ratio of public to private capital increases from 0.29 to 0.61 , thereby generating a huge investment boom in infrastructure. The increase in the stock of public capital increases the marginal productivity of private capital, thereby leading to a

\footnotetext{
${ }^{15}$ The choice of adjustment cost $h=15$ is consistent with Origueira and Santos (1997), who find that $h=16$ leads to a plausible speed of convergence of around 2\%. Auerbach and Kotlikoff (1987) assume $h=10$, recognizing that this is at the low values of estimates, while Barro and Sala-i-Martin (1995) propose a value above 10. We have also assumed smaller values of $h$, with little change in results. Note also that the equality of adjustment costs between the two types of capital serves as a plausible benchmark.
} 
positive, though lesser accumulation of private capital. Although the transfer stimulates consumption through the wealth effect, (like the pure transfer) the higher long-run productive capacity has a greater effect on output, leading to a decline in the long-run consumption-output ratio from 0.60 to 0.56 . The higher productivity raises the long-run growth rate to $1.94 \%$, while long run welfare improves by $9.8 \%$, as indicated in the last column of Row 3. The increased accumulation of both private and public capital lead to a higher demand for external borrowing as a means of financing new investment in private capital and the installation costs of public capital. This results in an increase in the steady state debt-output ratio from 0.45 to 0.77 , raising the borrowing premium to over $2.8 \%$. However, this higher debt relative to output is sustainable since it is caused by higher investment demand rather than higher consumption demand. The long run increase in the economy's productive capacity (as measured by the higher stocks of public and private capital, and output) ensures that the higher debt is sustainable. This view has also been expressed by Roubini and Wachtel (1998).

The transitional dynamic paths are depicted in Figure 1. Fig. 1.1 illustrates the stable adjustment-locus in $k_{g}$-n space, indicating how $k_{g}$ and $n$ increase almost proportionately during the transition. The contrasting transitional paths of the four growth rates $\phi_{K}, \phi_{G}, \phi_{Y}$ and $\phi_{C}$ toward their common long-run growth rate are shown in Fig 1.2. The stimulus to public capital raises its initial growth rate to over $6.7 \%$, after which it declines monotonically. By contrast, private capital adjusts only gradually. Indeed, after increasing on impact to $1.70 \%$, it declines marginally, before the stimulating effect of the higher public capital has its full impact and eventually raises its growth rate toward the equilibrium. The growth rate of output is an average of the growth rates of the two capital stocks. The fact that the growth rate of output initially doubles from $1.37 \%$ to $2.71 \%$ is of interest and is consistent with the experiences of some of the recipient countries, as noted in Section 2. Finally, the growth rate of consumption is unaffected on impact and responds only gradually. The reason for this is evident from (3a') and the fact 
that it depends upon the sluggishly evolving debt-capital ratio, $n .{ }^{16}$ Figures 1.3-1.5 illustrate the transition paths for the output-capital ratio, debt-output ratio, and the consumption-output ratio, respectively. The first two increase monotonically through time. This is because the accumulation of public capital raises the average productivity of private capital, while the accumulation of both types of capital raises the need to borrow from abroad. By contrast, the consumption-output ratio initially increases before declining through time. This is because the wealth effect associated with the transfer oductive capacity, through capital accumulation, takes time. ${ }^{17}$

Row 4 reports the effects of a bond-financed (or equivalently lump-sum tax financed) government expenditure increase on infrastructure in the absence of transfer flows. In order to draw a comparison with the case of a transfer shock, the magnitude of the government expenditure shock is equal to that of the transfer. We find that the two shocks have identical effects on the economy's long-run equilibrium in all but two respects. First, the government expenditure shock causes a larger crowding out of private consumption than does a transfer shock, with the consumption-output ratio declining to 0.51. This is because in contrast to the transfer of resources from abroad, the higher domestic government expenditure entails a direct appropriation of the economy's output, thereby decreasing the amount available for consumption. Second, as a consequence, the welfare gains from the higher government expenditure are also smaller than those from productive transfers. Welfare improves by only $0.3 \%$ in this case as against a $9.8 \%$ improvement from the transfer shock. The dynamics are generally similar qualitatively and are not illustrated. There is a minor change in the initial growth rate of private capital, which in turn is reflected in the initial growth rate of output, both of which rise

\footnotetext{
${ }^{16}$ Much of the recent literature on growth theory has emphasized the speed of convergence, that is the speed at which the economy converges to its steady state. We obtain an asymptotic speed of convergence of around 6\% which is plausible for an open economy. The speed is fairly insensitive to the form of the transfer and the form of policy response.

${ }^{17}$ We have also considered the time path for the instantaneous utility and find that it is uniformly higher at each instant of time with the tied transfer.
} 
marginally. This is a consequence of the reduction in private consumption stemming from the higher financing costs (either lump-sum taxation or borrowing). ${ }^{18}$

\subsection{Domestic Co-financing and Welfare Gains}

Rows 5 to 7 deal with the issue of domestic co-financing in response to a transfer shock, a feature that is common to all of the EU's structural funds programs. Row 5 requires the domestic government to match fully the contribution from abroad. The interesting point here is that this reduces the welfare gain to $4.7 \%$, the reason for this being that this forces the domestic government to devote $15 \%$ of output to public investment, making the public sector too large. If, instead, the transfer were untied, while forcing the equal co-financing, welfare would again be $9.83 \%{ }^{19}$

Alternatively, suppose that the domestic government accommodates the transfer shock by setting its own participation so as to maximize the long-run growth rate. That is, the tax and expenditure rates are set in accordance with (13). Assuming without any loss of generality that $\lambda=1$, this implies $\tau=0.16=\hat{\bar{g}}=0.16(=\hat{g}=0.21)$. Notably, this response causes the steady-state growth rate to nearly double from the benchmark value of $1.37 \%$ to $2.56 \%$. The short-run growth rates of public and private capital undergo similar large increases to nearly $3 \%$ and over $18 \%$ respectively, with the short-run growth rate of output increasing to over $6 \%$. This emphasis on growth and capital accumulation implies that there is less output available for consumption and indeed, the consumptionincome ratio drops to 0.38 . This is undesirable from an intertemporal welfare point of view; indeed, welfare drops by $8.6 \%$ relative to the benchmark. ${ }^{20}$

Row 7 describes the final response, namely where the government sets its tax and expenditure rates so as to maximize the welfare gains resulting from the transfer. Again

\footnotetext{
${ }^{18}$ The case where the increase in government investment is financed by a higher distortionary tax rate leads to generally similar responses, since with the externalities, the distortions are relatively small.

${ }^{19}$ In the case where the 5\% increase in public investment is financed evenly by the domestic government and foreign transfers, welfare improves by $5 \%$.

${ }^{20}$ This specific result does depend upon the magnitude of the adjustment costs. If, instead, $h_{1}=h_{2}=8$, we find that the growth-maximizing response is also welfare-improving relative to the benchmark.
} 
without loss of generality setting $\lambda=1$, the welfare-maximizing response is to set $g=\tau=0.02$, these values being obtained as solutions to (14) from numerical simulations of the model. This leads to a long-run growth rate of $2.1 \%$, with the short-run growth rates of public capital, private capital, and output, being moderated to $3.5 \%, 2.8 \%$ and $3 \%$ respectively. The consumption-output ratio is also correspondingly higher at 0.55 , with the corresponding intertemporal gain in welfare being 10.5\%. Comparing 6 and 7 we see that there is a dramatic tradeoff between growth maximization, on the one hand, and welfare maximization, on the other.

The dynamic adjustments with active co-financing are qualitatively similar to that illustrated in Fig 1 where the government responds passively. But there are some minor differences, which are brought out in Figs. 2. Fig. 2.1 compares the time paths of the growth rate of output under two regimes: (i) where the domestic government responds passively to the productive transfer and (ii) where the domestic government sets its participation at the welfare-maximizing level. We see that the time path of the growth rate of output is uniformly higher in the latter case. Fig. 2.2 illustrates the time paths of welfare gains (relative to the benchmark) for these two regimes. Here we see that there is a weak intertemporal tradeoff. By devoting more resources to investment in the short run, the optimal response reduces short-run consumption and utility in return for a significantly higher permanent growth rate and more consumption in the future (beyond 15 years).

\subsection{Some Sensitivity Analysis}

While the above parameters represent a plausible description of a small poorly endowed economy, some of the results are dependent upon this characterization. Tables 4 and 5 conduct some sensitivity analysis. Table 4 considers two alternative benchmark economies, corresponding to $g=0.12$ (large domestic government investment) and $g=$ 0.02 (small domestic government investment). In the first case, a tied transfer leads to a 
small welfare loss of $1.65 \%$, while additional domestically financed government expansion leads to a large welfare loss of $12.8 \%$. Furthermore, equal co-financing is even worse, leading to a welfare loss of $16.5 \%$, which is more than the sum of its two components. By contrast, the untied transfer is highly desirable, improving welfare by $10.5 \%$. The reason for this is such an economy is characterized by an overly large stock of public capital relative to private capital and a large foreign debt. It is clearly better off by reducing its debt and is only made worse off by increasing its stock of public capital.

For Benchmark III things are reversed. The country has only a small ratio of public to private capital and actually is a foreign creditor. Both the tied transfer, and the domestically financed government expenditure improve welfare dramatically $(31.6 \%$ and $21.5 \%$ respectively), and co-financing is even better. With small debt, the pure transfer is now only moderately welfare-improving, and indeed less so than for Benchmark II.

A natural question concerns the extent to which the gains from a foreign transfer depend upon (i) the installation costs associated with public capital, $\left(h_{2}\right)$, and (ii) the degree of imperfection of the world capital market (measured by $a$ ). Table 5 presents these gains for the two cases $\lambda=0$ and $\lambda=1$, for three values of each of these parameters, in the case that the domestic government acts passively. The values of $h_{2}=1,15$, and 40 correspond to low, medium, and high installation costs, while $a=0.03,0.10$, and 10 correspond to high, medium, and virtually no access to the world capital market. The percentage changes reported in the table refer to the benchmark that would correspond to the associated combination of parameters. Thus, for example, the figures in the top left hand corner imply that an economy for which $a=0.03, h_{2}=1$ will enjoy an $8.99 \%$ improvement in welfare if it experiences a $5 \%$ pure transfer, and a $20.85 \%$ welfare gain if the transfer is tied to investment in public capital. From this table we can make the following observations:

(i) For a given degree of imperfection in the world capital market (i.e. given $a$ ) an increase in the installation costs of public capital $\left(h_{2}\right)$ leads to larger welfare gains from a 
pure transfer of a given magnitude, but a decrease in welfare gains if the transfer is tied to public capital.

(ii) For given installation costs, an increase in the degree of imperfection in world capital markets in general leads to lower long run welfare gains from the transfer.

(iii) For very high installation costs the economy is better-off with a pure transfer: a tied or productive transfer is welfare-reducing in the long run, irrespective of the nature of world capital markets. However, in all other cases, welfare gains from productive transfers are higher than those from pure transfers.

The result in (iii) that under very high adjustment costs, a tied transfer is welfaredeteriorating is interesting. Intuitively, it reflects the fact that by tying the transfers, the donor country is committing the recipient country to devote a large portion of its resources to the costly task of installation, thereby making it worse off.

\section{Temporary Transfers}

Most transfer programs, whether pure or productive, are only temporary. Thus it is important to analyze the consequences of a temporary transfer. As before, we assume that the magnitude of the transfer is 5\% of the recipient country's GDP, and we focus on the polar cases of a pure transfer $(\lambda=0)$ and a fully-tied productive transfer $(\lambda=1)$, respectively. We assume that the duration of the transfer is 10 years, consistent with the average length of the EU's Structural Funds Programs.

The results of our experiments are reported in Table 6, and their dynamics are illustrated in Figures 3-5. The first four columns of Table 6 report the instantaneous impact of a temporary transfer on the growth rates of private and public capital, output, and consumption, respectively. Rows 1 and 2 describe the type of transfer shock, i.e., whether it is tied or pure in nature. 


\subsection{Pure Transfer}

We turn first to the pure transfer, reported in Row 1. Neither the growth rate of consumption nor debt responds immediately. In the case of consumption, the reason for this remains as for the permanent transfer; its growth rate is tied via the borrowing rate to the debt-capital ratio, $n$, which is constrained to evolve continuously over time. Similarly, when $\lambda=0,\left(5^{\prime \prime}\right)$ implies that the growth rate of public capital responds to the productivity of public capital, $Y / K_{G}$, which also evolves only gradually. By contrast, the growth rate of private capital, being determined by $q$, does respond on impact, increasing from $1.37 \%$ to $1.58 \%$. This is because with the transfer being only temporary, the initial response in the consumption-output ratio is dampened from 0.65 , if it were permanent, to just over 0.63 , thereby freeing some domestic output, which then becomes available for investment in private capital. The short-run higher growth rate of private capital raises the short-run growth rate of output to $1.54 \%$, this reflecting the relative importance of private capital in production.

In contrast to the permanent pure transfer, the adjustments are characterized by transitional dynamics. These can be understood by considering Fig 3.1, the phase diagram describing the dynamic adjustments of the ratio of public to private capital, $k_{g}$ and the debt-capital ratio $n$, in conjunction with the growth rates for, $K$ and $K_{G}$ illustrated in Fig. 3.2, and $N$, (not illustrated). ${ }^{21}$ Suppose that the economy starts out from the equilibrium point $\mathrm{A}$ in Fig. 3.1. Since the transfer has no impact on the initial growth of public capital, while leading to more private investment, the ratio of public capital to private capital, $k_{g}$, begins to decline. At the same time, while the untied transfers reduce the accumulation of debt, the higher investment and consumption has the opposite effect. On balance, the former effect dominates, and the initial growth rate of debt falls from its

\footnotetext{
${ }^{21}$ The reason for not illustrating the growth rate of $N$ is one of scale. Its growth rate is much larger (in magnitude) than that of $Y$, a fact that can be inferred from the $N / Y$ ratio illustrated in Fig. 3.3. Critical values are as follows. During the duration of the temporary pure transfer $\dot{N} / N$ declines from $0.5 \%$ to $7.8 \%$ till $\mathrm{t}=10$, when it immediately jumps to $+7.75 \%$ before converging back to the steady-state value of $1.37 \%$.
} 
benchmark value of $1.37 \%$ to $0.5 \%$, so that the debt-capital, $n$, ratio begins to decline as well. The economy therefore begins to move along the locus AB in Fig 3.1. During the early stages of the decline in $k_{g}$ and $n$, the growth rate of private capital continues to increase, though at a declining rate, reaching a peak at about 1.64\% after 6 periods, after which it too begins to decline. This is because the initial jump in $q$, together with the decline in $k_{g}$ reduces the rate of return on private capital, requiring $\dot{q}>0$, to ensure that the return on capital equals the cost on debt, which initially declines at a slower rate. The increase in the private capital stock raises the growth rate of output, thereby gradually increasing the growth of public capital, and thus slowing the decline in $k_{g}$. By contrast, as $n$ declines, the decline in the growth rate of debt accelerates dramatically, due primarily to the lower interest costs. After 10 periods, when the transfer ceases, the economy is at B. At that point, the growth rates of $K, K_{G}$, and $N$ are respectively $1.57 \%$, $1.46 \%$, and $-7.80 \%$. However, the removal of the transfer immediately raises the growth rate of debt to $7.75 \%$, so that the debt-capital ratio starts to increase. By contrast, with private capital still being accumulated at a faster rate than public capital, $k_{g}$ continues to decline, though with the former declining and the latter increasing, this decline ceases at time 15, when the economy is at $\mathrm{C}$. Thereafter, the reduced relative stock of public capital raises its productivity, encouraging public investment so that the economy returns to its original equilibrium along $\mathrm{CA}$, with both $k_{g}$ and $n$ increasing. From Fig. 3.2 the growth rates of output is seen to be an average of that of the two capital stocks, while the time path for the consumption growth rate reflects that of the time path of $n$.

Figures 3.3 - 3.5 illustrate the dynamic time paths of the consumption-output, debt-output, and capital-output ratios, respectively. These all mirror the differential growth rates as set out in Fig. 2. Thus, for example, the $K / Y$ ratio is increasing or decreasing, as long as the ratio $k_{g}$ is falling, or rising. Likewise the fact that $C / Y$ fall rapidly at first is because during this period $\mathrm{Y}$ is rising while $\mathrm{C}$ is falling; the decline is more gradual when the two growth rates are close to converging. 


\subsection{Tied-Transfer}

Row 2 of Table 6 reports the impact of a temporary tied (productive) transfer. Again, the growth rate of consumption does not respond instantaneously. However, the growth rates of all other variables respond instantaneously with the magnitudes of these initial jumps being significantly higher than for a pure transfer. Thus, the growth rate of private capital increases on impact to $1.74 \%$ as compared to $1.58 \%$ for a pure transfer. With the transfer being tied to public investment, the growth rate of public capital increases to $6.7 \%$, a sharp contrast to its sluggish response to a pure transfer. As a result, the growth rate of output goes up to $2.74 \%$ as against $1.54 \%$ for a pure transfer. It is interesting to observe that when compared to the corresponding jumps for a permanent productive transfer shock (see Table 3; columns 6-9), we find that a temporary productive transfer induces a marginally larger initial responses in growth rates than does a permanent shock of equal magnitude. Thus, in the short run, while the transfer program is in effect, strong positive differentials are created in growth rates relative to the benchmark. This result vindicates the objectives of the EU's temporary transfer programs discussed in section 2; empirically the magnitude is consistent with the growth rates experienced by Spain and Portugal as recipients of the EU transfer program.

The dynamics can be understood by considering Fig 3.1 in conjunction with the growth rates illustrated in Figs. 4.2. These indicate a dramatic contrast from those of the pure transfer; indeed the time paths for most variables are generally reversed. ${ }^{22}$ Suppose that the economy starts out at point A in Fig.4.1. With the dramatic increase in the growth rate of public capital, far exceeding that of private capital, the ratio of public to private capital begins to rise. At the same time, with the tied transfers being unavailable for debt reduction, the higher consumption and investment leads to a similar dramatic

\footnotetext{
${ }^{22}$ Again, the growth rate of $N$ cannot be conveniently illustrated in Fig 4.2, because of differences in magnitude, which are now even more dramatic. Critical values are now as follows. During the duration of the temporary tied transfer $\dot{N} / N$ declines form $24 \%$ to $1.8 \%$ at $\mathrm{t}=10$, when it immediately jumps to $5.8 \%$ before converging back to the steady-state value of $1.37 \%$.
} 
increase in the growth rate of debt, which increases at the rate of $24 \%$ on impact, so that the debt-capital ratio begins to rise sharply as well. The economy therefore begins to move along the locus ACB in Fig. 4.1. As $k_{g}$ and $n$ both increase, the growth rates of both public capital and debt decline dramatically, the latter more so, with the economy reaching $\mathrm{B}$ after 10 periods. The permanent elimination of the transfer at that time reverses the dynamics, taking the economy back to its original equilibrium along the locus BDA.

From Figure 4.2, we see that following the initial jump, the growth rates of public and private capital, and output start declining toward the benchmark growth rate. The growth rate of consumption, although unaffected initially, increases slightly in transition. At the end of the program, when the transfer flows cease, the growth rate of public capital jumps down below its benchmark level, after which it then increases back to its (unchanging) equilibrium level.

Figures 4.3-4.5 present the dynamic paths of the consumption-output, capitaloutput, and debt-output ratios respectively. These are all generally opposite to those for the pure transfer, reflecting the reversal in the dynamics of $k_{g}$ and $n$. One interesting difference arises with respect to the consumption-output ratio, which falls below its benchmark during the period the transfer is in effect. This is due to a short run substitution of consumption for capital accumulation. However, the end of the transfer program causes a reverse substitution towards consumption, and the ratio increases to its benchmark in the long run. The main general picture to emerge in comparing Figures 3 and 4, we see that the particular nature of the incoming transfer has important implications for the economy's dynamic adjustment, both in the short run as well as in the long run. In our case, the transitional dynamics of a pure transfer are very different from those of a productive transfer. 


\subsection{Permanent Effects of a Temporary Transfer Shock}

In this section we show how a temporary transfer program, by altering the growth rate during the transition, can have permanent effects on the levels of key variables such as the capital stock, output, and consumption of the recipient economy. In addition we show how the type of incoming transfer (pure or tied) affects the magnitude and direction of the permanent effects. Figure 5 and the last six columns of Table 6 report the permanent effects of temporary transfers. Specifically, we normalize the benchmark steady state level to unity and express the new steady state levels relative to the normalized benchmark. Thus, the ratio of 1.10 across steady states implies a $10 \%$ increase in levels relative to the benchmark.

Formally, we may let the after-shock time path of a variable $X$ be:

$$
X(t)=X(0) \operatorname{Exp}\left[\int_{0}^{T} \phi_{X}(s) d s+\int_{T}^{t} \phi_{X}(s) d s\right]
$$

where $\phi_{X}(t)$ is the growth rate of variable $X$, at time $t$, and which follows a different path while the temporary policy is in effect (until time $T$ ) and after it is removed. The corresponding time path of $X$ in the absence of the shock (the benchmark path) is then given by

$$
X_{b}(t)=X_{b, 0} \operatorname{Exp}\left(\phi_{b} t\right)
$$

where $X_{b}$ and $\phi_{b}$ denote the benchmark level of $X$ and $\phi$ respectively. Then the long run impact of the temporary shock on the level of $X$ relative to its benchmark is given by

$$
\frac{X(t)}{X_{b}(t)}=\frac{X(0)}{X_{b, 0}} \operatorname{Exp}\left[\int_{0}^{T}\left(\phi(s)-\phi_{b}\right) d s+\int_{T}^{t}\left(\phi(s)-\phi_{b}\right) d s\right]
$$


The shock growth rates and stationary variables return to their benchmark levels in the long run, the accumulated effects on the levels of these variables during transition may have significant permanent effects. ${ }^{23}$

For our experiments, $X=K, K_{g}, C, N, Y$, and the level of long run welfare, denoted by $W$. From columns 6-11 in Table 6 we see that temporary transfers do indeed have permanent effects on the levels of key economic variables. However, as the results reveal, the magnitude of the effects are different, depending upon the specific nature of the transfer. From Row 1 we see that a temporary pure transfer leads to only a $3 \%$ long run improvement in the stocks of private and public capital and in the levels of consumption and output. However, the debt position of the economy worsens by $4 \%$ in the long run. On the other hand, the long run effects of a productive transfer are less uniform and larger in magnitude. Row 2 indicates that a temporary productive transfer increases the long run stocks of private and public capital by $7 \%$ and $10 \%$ respectively. Consumption and output increase by $7 \%$ and $8 \%$ respectively. For both types of transfer, the effects on intertemporal welfare are substantial being $4.4 \%$ and $5 \%$, respectively. The relatively small difference is due to the fact that the greater benefits associated with the tied transfer occur through time and therefore are discounted. The long-run debt position of the economy actually improves by $36 \%$. This is in contrast to the result for pure transfers: a temporary productive transfer improves the current account permanently, while a pure transfer causes a permanent deterioration of the current account. This is due to the fact that the increase in long run productive capacity, as measured by the long run changes in the stock of private and public capital, and the level of output, is much larger for a productive shock. The higher long run productive capacity enables the economy to improve its long-run debt position. The above results are graphically represented in Fig.5.

\footnotetext{
${ }^{23}$ Note that $K, K_{g}, Y$, and $N$ evolve continuously at $t=0$, so that for these variables $X(0) / X_{b, 0}=1$. In contrast, $C$ and $W$ undergo jumps at time 0 . These differences are illustrated in Fig. 5.
} 


\section{Conclusions}

In this paper we have addressed an important topical issue, namely the impact of a program of tied transfers, such as those implemented recently by the EU, on the growth and macroeconomic performance of the recipient country. The effects of both permanent and temporary transfers have been considered, the former serving as a benchmark, the latter being a closer representation of actual policies.

The main general conclusion to emerge is that there is a sharp contrast in the effects of pure transfers of the traditional Keynes-Ohlin type and the current program of tied transfers adopted by the European Union. A permanent pure transfer has no growth or dynamic consequences. It is always welfare-improving, the gains varying positively with the size of the government, when the stock debt and the benefits of debt reduction increase. A tied transfer generates dynamic adjustments, as public capital is accumulated in the recipient economy. Its effect on the long-run growth rate, and the extent to which this is beneficial, depends upon the size of the infrastructure in the economy, as well as the co-financing arrangements, if any, imposed on that economy, and how its government chooses to react to the additional flow of resources. For what we consider to be the most applicable case of an economy relatively poorly endowed with public capital, a tied transfer will both raise the long-run growth rate and yield greater intertemporal benefits than does a pure transfer. However, the benefits from an equal co-financing, similar to that proposed by the EU, are substantially smaller than if no such arrangement were imposed. If the economy is relatively well endowed with government capital a tied transfer is welfare-deteriorating, and is particularly harmful if it involves domestic cofinancing.

These contrasts also apply to temporary transfers, and in particular to the transitional dynamics in the two cases. Whereas a temporary pure transfer has only a modest short-run growth effect, the productive transfer has significant impacts on shortrun growth thus validating the position taken by the EU. Both transfers, although only 
temporary, have permanent effects on levels, with those of the tied shock being significantly greater. For example, for the benchmark economy we find that a 10 year tied transfer of 5\% of the recipient economy's GDP raises long-run output by $8 \%$ and its welfare by $5 \%$, values we find to be significant.

We conclude with two final comments. First, the fact that the effects of the tied transfer are less certain than those of the pure transfer, depending upon the size of the government in the recipient economy suggests that the donor economy must be careful to ensure that it has accurate information on the recipient economy. If it operates with inaccurate information, then it may lead to a deterioration in the recipient economy. Second, we should note that we have focused on the effects of the transfer on the economic performance of a small recipient economy. Being small, this has no feedback on the donor economy. However, such transfers are being proposed simultaneously for a number of prospective member nations, the collective feedback effects of which on the donor economy need no longer be negligible. A natural extension of this analysis is, therefore, to consider the transfer in a multi-country growth equilibrium setting. 


\section{REFERENCES}

Aschauer, D.A. (1989a), "Is Public Expenditure Productive?" Journal of Monetary Economics 23, 177-200.

Aschauer, D.A. (1989b), "Does Public Capital Crowd Out Private Capital?," Journal of Monetary Economics 24, 171-188.

Auerbach, A.J. and L.J. Kotlikoff (1987), Dynamic Fiscal Policy, Cambridge UK, Cambridge University Press.

Bardhan, P.K. (1967), “Optimal Foreign Borrowing,” in K. Shell (ed.), Essays on the Theory of Optimal Economic Growth," MIT Press, Cambridge MA.

Barro, R.J. (1990), "Government Spending in a Simple Model of Endogenous Growth," Journal of Political Economy 98, 103-125.

Barro,R.J. and X. Sala-i-Martin (1995), Economic Growth, NY, McGraw-Hill.

Baxter, M., and R.G. King (1993), "Fiscal Policy in General Equilibrium," American Economic Review 83, 315-334.

Bhagwati, J.N., R.A. Brecher, and T. Hatta (1983), “The Generalized Theory of Transfers and Welfare: Bilateral Transfers in a Multilateral World," American Economic Review, Sept., 606-618.

Bhagwati, J.N., R.A. Brecher, and T. Hatta (1985), “The Generalized Theory of Transfers and Welfare: Exogenous and Endogenous Distortions," Quarterly Journal of Economics 100(3), 697-714.

Bhandari, J.S., N.U. Haque, and S.J. Turnovsky (1990), "Growth, External debt, and Sovereign risk in a Small Open Economy,” IMF Staff Papers 37, 388-417.

Brock, P. L. (1996), "International Transfers, the Relative Price of Non-Traded Goods, and the Current Account," Canadian Journal of Economics 29, 163-180. 
Cooper, R.N. and J. Sachs (1985), "Borrowing Abroad: the Debtor's Perspective," in G.W. Smith and J.T. Cuddington (eds.), International Debt and Developing Countries, World Bank, Washington, DC.

Devarajan, S., D. Xie and H. Zou (1998), "Should Public Capital be Subsidized or Journal of Monetary Economics 41, 319-331.

Eaton, J. and M. Gersovitz (1989), “Country Risk and the Organization of International R. Findlay, P. Kouri, and J. Braga de Macedo (eds.), Debt, Stabilization and Development: Essays in Memory of Carlos DiazAlejandro, Blackwell, Oxford, UK.

Edwards, S. (1984), "LDC Foreign Borrowing and Default Risk: An Empirical Investigation 1976-80," American Economic Review 74, 726-734.

Eicher, T. S. and S. J. Turnovsky (1999), "Convergence in a Two-Sector Non-Scale Growth Model," Journal of Economic Growth, 4, 413-428.

European Union (1998), Council Regulation for an Instrument for Structural Policies for Pre-Accession. Draft Proposal.

European Union (1998), Commission Communication to the Council and to the European Parliament on the Establishment of a New Financial Perspective for the Period 2000-2006.

Fisher, W.H. and S.J. Turnovsky (1998), "Public Investment, Congestion, and Private Capital Accumulation," Economic Journal 108, 339-413.

Futagami, K., Morita, Y., and Shibata, A. (1993), "Dynamic Analysis of an Endogenous Growth Model with Public Capital," Scandinavian Journal of Economics 95(4), 607-625.

Galor, O. and H. M. Polemarchakis (1987), "Intertemporal Equilibrium and the Transfer Review of Economic Studies 54, 147-156.

Glomm, G. and B. Ravikumar (1994), "Public Investment in Infrastructure in a Simple Journal of Economic Dynamics and Control 18, 1173-1187. 
Gramlich, E.M. (1994), "Infrastructure Investment: A Review Essay," Journal of Economic Literature 32, 1176-1196.

Haaparanta P., (1989), "The Intertemporal Effects of International Transfers," Journal of International Economics, 26, 371-382.

Hulten, C.R. (1996), "Infrastructure Capital and Economic Growth: How Well You Use it May Be More Important Than How Much You Have," NBER Working Paper 5847.

Keynes, J.M. (1929), “The German Transfer Problem,” Economic Journal 39, 1-7.

Obstfeld, M. (1982), "Aggregate Spending and the Terms of Trade: Is There a LaursenMetzler Effect?" Quarterly Journal of Economics 97, 251-270.

Economic Journal 39, $172-178$.

Ortigueira, S. and M.S. Santos (1997), "On the Speed of Convergence in Endogenous Growth Models, American Economic Review 87, 383-399.

Pereira, A. M. (1997), "Development Policies in the EU: An International Comparison," Review of Development Economics 1, 219-235.

Pigou, A.C. (1932), "The Effect of Reparations on the Ratio of International Economic Journal 42, 532-543.

Rebelo, S. (1991), "Long-run Policy Analysis and Long-run Growth," Journal of Political Economy 94, 1002-1037.

Roubini, N., and P. Wachtel (1998), "Current Account Sustainability in Transition Economies,” NBER Working Paper 6468.

Sachs, J. (1984), "Theoretical Issues in International Borrowing International Finance, 54.

Samuelson, P. A. (1952), "The Transfer Problem and Transport Costs: The Terms of Trade When Impediments are Absent," Economic Journal 59, 181-197.

Samuelson, P. A. (1954), "The Transfer Problem and Transport Costs II: Analysis of Economic Journal 64, 254-289. 
Turnovsky, S. J. (1997a), "Public and Private Capital in an Endogenously Growing Open -Y. Wong (eds.), Dynamics, Economic Growth, and International Trade, University of Michigan Press, Ann Arbor.

Turnovsky, S. J., (1997b), International Macroeconomic Dynamics. MIT Press, Cambridge.

Turnovsky, S.J. (1997c), "Public and Private Capital in an Endogenously Growing Macroeconomic Dynamics 1, 615-639.

Turunen-Red, A.H. and A.D. Woodland (1988), “On the Multilateral Transfer Problem: Existence of Pareto Improving International Transfers," Journal of International Economics 25, 249-269.

World Bank (1994), World Development Report 1994: Infrastructure for Development. Oxford University Press, New York. 


\section{APPENDIX}

\section{Appendix A1. Characterization of Transitional Dynamics ${ }^{24}$}

In section 3.2 we showed that equilibrium in this economy is saddle-point stable with two unstable and two stable roots. The stable roots were denoted by $\mu_{1}$ and $\mu_{2}$ with $\mu_{2}<\mu_{1}<0$. Corresponding to the two stable and two unstable roots the system is characterized by two state ("sluggish") variables, $k$ and $n$, and two control ("jump") variables, $q$ and $c$. Since, the stock of public capital relative to private capital $(k)$ and the stock of debt relative to private capital (n) are constrained to evolve continuously, we focus on them in order to characterize the transitional dynamics of the system. The generic form of the stable solutions for these variables is given by:

$$
\begin{aligned}
& k(t)-\tilde{k}=\Omega_{1} e^{\mu_{1} t}+\Omega_{2} e^{\mu_{2} t} \\
& n(t)-\tilde{n}=\Omega_{1} \xi_{21} e^{\mu_{1} t}+\Omega_{2} \xi_{22} e^{\mu_{2} t}
\end{aligned}
$$

where $\Omega_{1}$ and $\Omega_{2}$ are constants to be obtained from initial conditions and they depend upon the specific shocks. The vector $\left(1, \xi_{2 i}, \xi_{3 i}, \xi_{4 i}\right) i=1,2$ is the normalized eigenvector associated with the stable eigenvalue, $\mu_{i}$.

Suppose the economy starts out with given initial stocks of public capital and debt relative to private capital, $\left(k_{0}, n_{0}\right)$, and through some policy shock converges to $(\tilde{k}, \tilde{n})$. Setting $t=0$ in (A2.1a) and (A2.1b) and letting $d \tilde{k} \equiv \tilde{k}-k_{0}, d \tilde{n} \equiv \tilde{n}-n_{0}$, the constants $\Omega_{1}$ and $\Omega_{2}$ are derived as:

$$
\Omega_{1}=\frac{d \tilde{n}-\xi_{22} d \tilde{k}}{\xi_{22}-\xi_{21}} ; \Omega_{2}=\frac{\xi_{21} d \tilde{k}-d \tilde{n}}{\xi_{22}-\xi_{21}}
$$

The slope of the transitional adjustment locus in the $n-k$ space is given by

\footnotetext{
${ }^{24}$ This section draws from Eicher and Turnovsky (1999).
} 


$$
\frac{d n}{d k}=\frac{\Omega_{1} \xi_{21} \mu_{1} e^{\mu_{1} t}+\Omega_{2} \xi_{22} \mu_{2} e^{\mu_{2} t}}{\Omega_{1} \mu_{1} e^{\mu_{1} t}+\Omega_{2} \mu_{2} e^{\mu_{2} t}}
$$

It is evident from (A2.1d) that the slope of the transitional path is time-varying. Since $\mu_{2}<\mu_{1}<0$, as $t \rightarrow \infty$ this converges to the new steady-state along the direction $(d n / d k)_{t \rightarrow \infty}=\xi_{21}$, for all admissible shocks. The initial direction of motion, however, depends upon the source of the shock and can be obtained by setting $t=0$ in (A2.1d).

Using (A2.1a) and (A2.1b) we can express the dynamics of the state variables in phase-space form:

$$
\left(\begin{array}{c}
\dot{k} \\
\dot{n}
\end{array}\right)=\left(\begin{array}{cc}
\frac{\left(\mu_{1} \xi_{22}-\mu_{2} \xi_{21}\right)}{\xi_{22}-\xi_{21}} & \frac{\left(\mu_{2}-\mu_{1}\right)}{\xi_{22}-\xi_{21}} \\
\frac{\left(\mu_{1}-\mu_{2}\right) \xi_{21} \xi_{22}}{\xi_{22}-\xi_{21}} & \frac{\left(\mu_{2} \xi_{22}-\mu_{1} \xi_{21}\right)}{\xi_{22}-\xi_{21}}
\end{array}\right)\left(\begin{array}{l}
k-\tilde{k} \\
n-\tilde{n}
\end{array}\right)
$$

By construction, the trace of the matrix in $(\mathrm{A} 2.1 \mathrm{e})=\mu \quad \mu_{2}<0$

$\mu_{1} \mu_{2}>0$, so that (A2.1e) describes a stable node. ${ }^{25}$

\section{Appendix A2. Solutions for a Temporary Shock}

Suppose the economy starts off from steady state at time 0 , with $\sigma=0$, and $k(0)=k_{0}, n(0)=n_{0}$. At time 0 , transfers increase from $\sigma=0$ to $\sigma=\sigma_{1}>0$. It remains at this level until time $t=T$, when it is restored back to its initial level of zero. We therefore consider the dynamics over two periods : (1) the period $(0, T)$, when the shock is in effect, and (2) the period after $T$, when the policy is permanently removed.

The dynamic time paths of $k, n, q$, and $c$ over the period $(0, T)$ are given by the following equations:

$$
k(t)=\tilde{k}_{2}+\Omega_{1}^{\prime} e^{\mu_{1} t}+\Omega_{2}^{\prime} e^{\mu_{2} t}+\Omega_{3}^{\prime} e^{\mu_{3} t}+\Omega_{4}^{\prime} e^{\mu_{4} t}
$$




$$
\begin{gathered}
n(t)=\tilde{n}_{2}+\Omega_{1}^{\prime} \xi_{21} e^{\mu_{1} t}+\Omega_{2}^{\prime} \xi_{22} e^{\mu_{2} t}+\Omega_{3}^{\prime} \xi_{23} e^{\mu_{3} t}+\Omega_{4}^{\prime} \xi_{24} e^{\mu_{4} t} \\
q(t)=\tilde{q}_{2}+\Omega_{1}^{\prime} \xi_{31} e^{\mu_{1} t}+\Omega_{2}^{\prime} \xi_{32} e^{\mu_{2} t}+\Omega_{3}^{\prime} \xi_{33} e^{\mu_{3} t}+\Omega_{4}^{\prime} \xi_{34} e^{\mu_{4} t} \\
c(t)=\tilde{c}_{2}+\Omega_{1}^{\prime} \xi_{41} e^{\mu_{1} t}+\Omega_{2}^{\prime} \xi_{42} e^{\mu_{2} t}+\Omega_{3}^{\prime} \xi_{43} e^{\mu_{3} t}+\Omega_{4}^{\prime} \xi_{44} e^{\mu_{4} t}
\end{gathered}
$$

where $k_{2}, \tilde{n}_{2}, \tilde{q}_{2}, \tilde{c}_{2}$ are the corresponding steady state values if the shock were to be permanent. Now, for the transversality conditions to be met, the dynamics over the period $(T, \infty)$ must be stable:

$$
\begin{gathered}
k(t)=\tilde{k}+\Omega_{1} e^{\mu_{1} t}+\Omega_{2} e^{\mu_{2} t} \\
n(t)=\tilde{n}_{2}+\Omega_{1} \xi_{21} e^{\mu_{1} t}+\Omega_{2} \xi_{22} e^{\mu_{2} t} \\
q(t)=\tilde{q}_{2}+\Omega_{1} \xi_{31} e^{\mu_{1} t}+\Omega_{2} \xi_{32} e^{\mu_{2} t} \\
c(t)=\tilde{c}_{2}+\Omega_{1} \xi_{41} e^{\mu_{1} t}+\Omega_{2} \xi_{42} e^{\mu_{2} t}
\end{gathered}
$$

We now have six equations in six unknowns: $\Omega_{i}^{\prime}, i=1$ to 4 , and $\Omega_{j}, j=1$ to 2 . These constants are determined by (1) initial conditions on $k$ and $n$, and (2) continuity conditions on $k, q, n$, and $c$. Thus setting $t=0$ in (A.2.1) and (A.2.2), and equating (A2.1) and (A2.5), (A2.2) and (A2.6), (A2.3) and (A2.7), (A2.4) and (A2.8) at time $t=T$ we get:

$$
\begin{gathered}
k_{0}-\tilde{k}_{2}=\Omega_{1}^{\prime}+\Omega_{2}^{\prime}+\Omega_{3}^{\prime}+\Omega_{4}^{\prime} \\
n_{0}-\tilde{n}_{2}=\Omega_{1}^{\prime} \xi_{21}+\Omega_{2}^{\prime} \xi_{22}+\Omega_{3}^{\prime} \xi_{23}+\Omega_{4}^{\prime} \xi_{24} \\
k_{2}+\Omega_{1}^{\prime} e^{\mu_{1} T}+\Omega_{2}^{\prime} e^{\mu_{2} T}+\Omega_{3}^{\prime} e^{\mu_{3} T}+\Omega_{4}^{\prime} e^{\mu_{4} T}=k+\Omega_{1} e^{\mu_{1} T}+\Omega_{2} e^{\mu_{2} T} \\
n_{2}+\Omega_{1}^{\prime} \xi_{21} e^{\mu_{1} T}+\Omega_{2}^{\prime} \xi_{22} e^{\mu_{2} T}+\Omega_{3}^{\prime} \xi_{23} e^{\mu_{3} T}+\Omega_{4}^{\prime} \xi_{24} e^{\mu_{4} T}=\tilde{n}+\Omega_{1} \xi_{21} e^{\mu_{1} T}+\Omega_{2} \xi_{22} e^{\mu_{2} T} \\
q_{2}+\Omega_{1}^{\prime} \xi_{31} e^{\mu_{1} T}+\Omega_{2}^{\prime} \xi_{32} e^{\mu_{2} T}+\Omega_{3}^{\prime} \xi_{33} e^{\mu_{3} T}+\Omega_{4}^{\prime} \xi_{34} e^{\mu_{4} T}=\tilde{q}_{2}+\Omega_{1} \xi_{31} e^{\mu_{1} T}+\Omega_{2} \xi_{32} e^{\mu_{2} T} \\
c_{2}+\Omega_{1}^{\prime} \xi_{41} e^{\mu_{1} T}+\Omega_{2}^{\prime} \xi_{42} e^{\mu_{2} T}+\Omega_{3}^{\prime} \xi_{43} e^{\mu_{3} T}+\Omega_{4}^{\prime} \xi_{44} e^{\mu_{4} T}=\tilde{c}+\Omega_{1} \xi_{41} e^{\mu_{1} T}+\Omega_{2} \xi_{42} e^{\mu_{2} T}
\end{gathered}
$$

\footnotetext{
${ }^{25}$ Note that the representation of the transitional dynamics in the $n-k$ space takes full account of the feedback arising from the jump variables $q$ and $c$; these are incorporated in the two eigenvalues.
} 
TABLE 1

Steady State Effects of Changes in Transfers and Fiscal Shocks

A. Permanent Increase in Transfers.

$$
\begin{aligned}
& \frac{d \tilde{k}}{d \sigma}=\frac{\lambda \alpha r^{\prime}(\tilde{n})}{J}\left[\frac{\tilde{q}}{h_{1}}+\frac{r(\tilde{n})-(\tilde{q}-1) / h_{1}}{(1-\gamma)} \tilde{k}_{g}^{\eta-1}>0\right. \\
& \frac{d \tilde{q}}{d \sigma}=\frac{\lambda \alpha r^{\prime}(\tilde{n})}{J} \frac{\eta(1-\tau)(1-\eta) \alpha \tilde{k}^{\eta-1}}{(1-\gamma)} \tilde{k}^{\eta-1}>0 \\
& \frac{d \tilde{n}}{d \sigma}=\frac{\lambda \alpha}{J} \frac{\eta(1-\tau)(1-\eta) \alpha \tilde{k}^{\eta-1}}{h_{1}} \tilde{k}_{g}^{\eta-1}=\frac{(1-\gamma)}{h_{1} r^{\prime}(\tilde{n})} \frac{d \tilde{q}}{d \sigma}>0
\end{aligned}
$$

B. Permanent Increase in Domestic Government Spending.

$$
\begin{aligned}
& \frac{d \tilde{k}}{d \bar{g}}=\frac{\alpha r^{\prime}(\tilde{n})}{J}\left[\frac{\tilde{q}}{h}+\frac{r(\tilde{n})-(\tilde{q}-1) / h_{1}}{(1-\gamma)}\right] \tilde{k}^{\eta-1}=\frac{1}{\lambda} \frac{d \tilde{k}}{d \sigma}>0 . \\
& \frac{d \tilde{q}}{d \bar{g}}=\frac{\alpha r^{\prime}(\tilde{n})}{J}\left[\frac{\eta(1-\tau)(1-\eta) \alpha \tilde{k}^{\eta-1}}{(1-\gamma)}\right] \tilde{k}^{\eta-1}=\frac{1}{\lambda} \frac{d \tilde{q}}{d \sigma}>0 . \\
& \frac{d \tilde{n}}{d \bar{g}}=\frac{\alpha}{J}\left[\frac{\eta(1-\tau)(1-\eta) \alpha \tilde{k}^{\eta-1}}{h_{1}}\right] \tilde{k}^{\eta-1}=\frac{1}{\lambda} \frac{d \tilde{n}}{d \sigma}>0 .
\end{aligned}
$$

C. Permanent Increase in the Income Tax Rate.

$$
\begin{aligned}
& \frac{d \tilde{k}}{d \tau}=\frac{\alpha r^{\prime}(\tilde{n})(1-\eta) \tilde{k}^{\eta}}{J h_{1}(1-\gamma)}>0 . \\
& \frac{d \tilde{q}}{d \tau}=-\frac{\alpha^{2}(1-\eta)^{2} r^{\prime}(\tilde{n})(\bar{g}+\lambda \sigma) \tilde{k}^{2 \eta-2}}{J(1-\gamma)}<0 . \\
& \frac{d \tilde{n}}{d \tau}=-\frac{(1-\eta)^{2} \alpha^{2} \tilde{k}^{2 \eta-2}}{J h_{1}}<0 .
\end{aligned}
$$


TABLE 3

Responses to Permanent Changes

\begin{tabular}{|l|l|l|l|l|l|l|l|l|l|l|l}
\hline & $k_{g}$ & \multicolumn{1}{r}{$\%$} & $\tilde{C /} Y$ & $\tilde{N} Y$ & $\tilde{Y / K}$ & $\begin{array}{c}\phi_{K}(0) \\
\%\end{array}$ & $\begin{array}{c}\phi_{G}(0) \\
\%\end{array}$ & $\begin{array}{c}\phi_{Y}(0) \\
\%\end{array}$ & $\begin{array}{c}\phi_{C}(0) \\
\%\end{array}$ & $\begin{array}{c}\tilde{\phi} \\
\%\end{array}$ & $\begin{array}{c}\Delta(W) \\
\%\end{array}$ \\
\hline $\begin{array}{l}\text { Benchmark } \\
\sigma=0, \lambda=0, \\
g=0.05, \tau=0.15\end{array}$ & $\mathbf{0 . 2 9 1}$ & $\mathbf{7 . 4 2 3}$ & $\mathbf{0 . 6 0 1}$ & $\mathbf{0 . 4 5 2}$ & $\mathbf{0 . 3 1 2}$ & $\mathbf{1 . 3 7}$ & $\mathbf{1 . 3 7}$ & $\mathbf{1 . 3 7}$ & $\mathbf{1 . 3 7}$ & $\mathbf{1 . 3 7}$ & $\ldots$ \\
\hline $\begin{array}{l}\text { Pure transfer } \\
\sigma=0.05, \lambda=0, \\
g=0.05, \tau=0.15\end{array}$ & 0.291 & 7.423 & 0.651 & 0.452 & 0.312 & 1.37 & 1.37 & 1.37 & 1.37 & 1.37 & +8.32 \\
\hline $\begin{array}{l}\text { Tied-transfer } \\
\sigma=0.05, \lambda=1, \\
g=0.05, \tau=0.15\end{array}$ & 0.610 & 8.845 & 0.561 & 0.774 & 0.362 & 1.701 & 6.739 & 2.71 & 1.37 & 1.938 & +9.83 \\
\hline $\begin{array}{l}\text { Bond-financed } \\
\text { Gov. exp. Increase } \\
\sigma=0, \lambda=0, \\
g=0.10, \tau=0.15\end{array}$ & 0.610 & 8.845 & 0.511 & 0.774 & 0.362 & 1.71 & 6.739 & 2.72 & 1.37 & 1.938 & +0.30 \\
\hline $\begin{array}{l}\text { Co-financing } \\
\sigma=0.05, \lambda=1, \\
g=0.10, \tau=0.15\end{array}$ & 0943 & 9.738 & 0.474 & 0.929 & 0.395 & 2.176 & 13.69 & 4.16 & 1.37 & 2.295 & +4.71 \\
\hline $\begin{array}{l}\text { Growth-max. } \\
\text { Govt. response } \\
\sigma=0.05, \lambda=1, \\
g=0.16, \tau=0.16\end{array}$ & 1.362 & 10.41 & 0.379 & 1.013 & 0.425 & 2.57 & 18.55 & 5.77 & 1.37 & 2.562 & -8.63 \\
\hline $\begin{array}{l}\text { Welfare-max. } \\
\text { Govt. response } \\
\sigma=0.05, \lambda=1, \\
g=.02, \tau=.02\end{array}$ & 0.376 & 9.31 & 0.545 & 0.989 & 0.329 & 2.82 & 3.52 & 2.96 & 1.37 & 2.12 & +10.49 \\
\hline
\end{tabular}


TABLE 4

Alternative Benchmarks

\begin{tabular}{|c|c|c|c|c|}
\hline & $\tilde{k}_{g}$ & $\frac{\tilde{N}}{\tilde{Y}}$ & $\tilde{\phi} \%$ & $\Delta(W) \%$ \\
\hline $\begin{array}{c}\text { Benchmark II } \\
\sigma=0, \lambda=0 \\
\mathrm{~g}=0.12, \tau=0.15\end{array}$ & 0.742 & 0.846 & 2.096 & --- \\
\hline $\begin{array}{c}\text { Pure Transfer } \\
\sigma=0.05, \lambda=0 \\
\mathrm{~g}=0.12, \tau=0.15\end{array}$ & 0.742 & 0.846 & 2.096 & +10.50 \\
\hline $\begin{array}{c}\text { Tied Transfer } \\
\sigma=0.05, \lambda=1 \\
\mathrm{~g}=0.12, \tau=0.15\end{array}$ & 1.077 & 0.972 & 2.410 & -1.65 \\
\hline $\begin{array}{c}\text { Bond-financed } \\
\text { Gov. Exp. Increase } \\
\sigma=0, \lambda=0 \\
\mathrm{~g}=0.17, \tau=0.15\end{array}$ & 1.077 & 0.972 & 2.410 & -12.76 \\
\hline $\begin{array}{c}\text { Co-finance } \\
\sigma=0.05, \lambda=1 \\
\mathrm{~g}=0.17, \tau=0.15\end{array}$ & 1.417 & 1.054 & 2.651 & -16.54 \\
\hline $\begin{array}{c}\text { Benchmark III } \\
\sigma=0, \lambda=0 \\
\mathrm{~g}=0.02, \tau=0.15\end{array}$ & 0.109 & -0.103 & 0.069 & --- \\
\hline $\begin{array}{c}\text { Pure Transfer } \\
\sigma=0.05, \lambda=0 \\
\mathrm{~g}=0.02, \tau=0.15\end{array}$ & 0.109 & -0.103 & 0.069 & +7.56 \\
\hline $\begin{array}{c}\text { Tied Transfer } \\
\sigma=0.05, \lambda=1 \\
\mathrm{~g}=0.02, \tau=0.15\end{array}$ & 0.417 & 0.618 & 1.634 & +31.62 \\
\hline $\begin{array}{c}\text { Bond-financed } \\
\text { Gov. Exp. Increase } \\
\sigma=0, \lambda=0 \\
\mathrm{~g}=0.07, \tau=0.15\end{array}$ & 0.417 & 0.618 & 1.634 & +21.46 \\
\hline $\begin{array}{c}\text { Co-finance } \\
\sigma=0.05, \lambda=1 \\
\mathrm{~g}=0.07, \tau=0.15\end{array}$ & 0.742 & 0.846 & 2.096 & +36.55 \\
\hline
\end{tabular}




\section{TABLE 5}

Welfare Sensitivity to Installation Costs and Capital Market Imperfections

$$
(\sigma=0 \text { to } \sigma=0.05 ; \lambda=1)
$$

\begin{tabular}{|c|c|c|c|c|c|c|}
\hline \multirow{2}{*}{} & \multicolumn{2}{|c|}{$h_{2}=1$} & \multicolumn{2}{c|}{$h_{2}=15$} & \multicolumn{2}{c|}{$h_{2}=40$} \\
\cline { 2 - 7 } & $\lambda=0$ & $\lambda=1$ & $\lambda=0$ & $\lambda=1$ & $\lambda=0$ & $\lambda=1$ \\
\hline \multirow{2}{*}{$a=0.03$} & $8.99 \%$ & $20.85 \%$ & $9.3 \%$ & $13.16 \%$ & $9.92 \%$ & $-1.89 \%$ \\
\hline \multirow{2}{*}{$a=0.10$} & $8.06 \%$ & $16.26 \%$ & $8.32 \%$ & $9.83 \%$ & $8.81 \%$ & $-2.39 \%$ \\
\hline \multirow{2}{*}{$a=10$} & $7.73 \%$ & $15.32 \%$ & $7.96 \%$ & $9.47 \%$ & $8.41 \%$ & $-1.5 \%$ \\
\hline
\end{tabular}




\section{Key Responses to a Temporary Transfer Shock}

Benchmark Steady State : $\lambda=0 ; \sigma=0 ; g=0.05 ; \tau=0.15 ; \mathrm{T}=10$ years.

\begin{tabular}{|c|c|c|c|c|c|c|c|c|c|c|c|}
\hline & \multicolumn{5}{|c|}{$\begin{array}{c}\text { Initial Response of Growth Rates of } \\
\text { Key Variables }\end{array}$} & \multicolumn{6}{|c|}{$\begin{array}{l}\text { Permanent Gains/Losses (Relative to } \\
\text { the Benchmark) Across Steady States } \\
\text { (Benchmark = 1) }\end{array}$} \\
\hline & $\begin{array}{l}\phi_{K}(0) \\
\%\end{array}$ & $\begin{array}{c}\phi_{g}(0) \\
\%\end{array}$ & $\begin{array}{c}\phi_{C}(0) \\
\%\end{array}$ & $\begin{array}{c}\phi_{Y}(0) \\
\%\end{array}$ & $\begin{array}{l}\tilde{\phi} \\
\%\end{array}$ & $K$ & $K_{g}$ & $C$ & $N$ & $Y$ & $\begin{array}{c}W \\
(\% \Delta)\end{array}$ \\
\hline $\begin{array}{l}\text { Pure } \\
\text { Transfer } \\
\lambda=0 ; \\
\sigma=0.05\end{array}$ & 1.58 & 1.37 & 1.37 & 1.54 & 1.37 & 1.03 & 1.03 & 1.03 & 1.04 & 1.03 & 4.39 \\
\hline $\begin{array}{l}\text { Productive } \\
\text { Transfer } \\
\lambda=1 ; \\
\sigma=0.05\end{array}$ & 1.74 & 6.74 & 1.37 & 2.74 & 1.37 & 1.07 & 1.10 & 1.07 & 0.64 & 1.08 & 4.97 \\
\hline
\end{tabular}




$$
\lambda=1 ; \sigma=0.05
$$

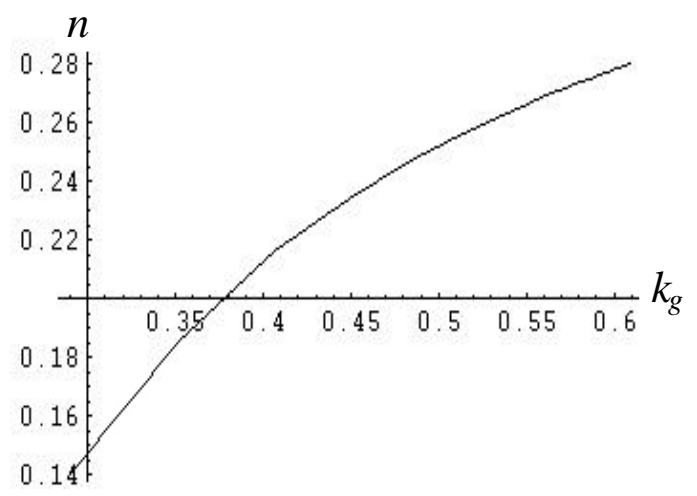

Figure 1.1. Transitional Adjustment Locus.

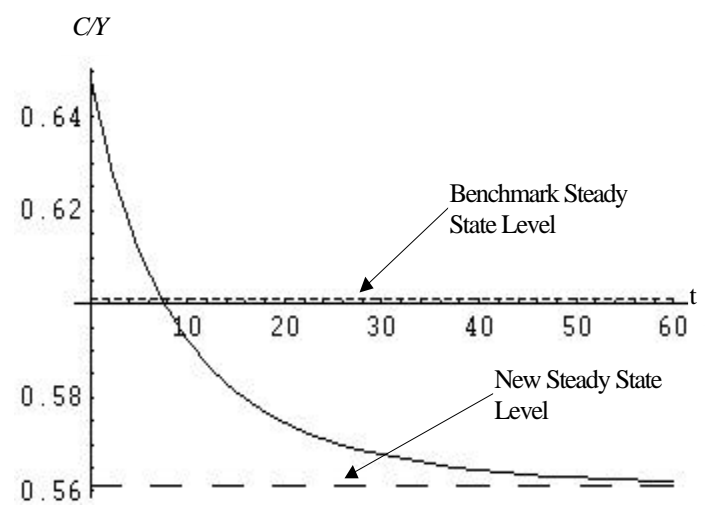

Figure 1.3. Consumption-Output Ratio.

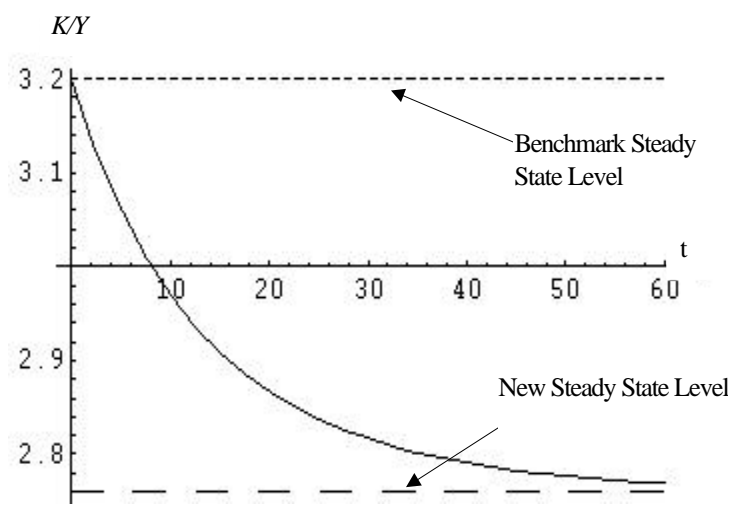

Figure 1.5. Capital-Output Ratio.

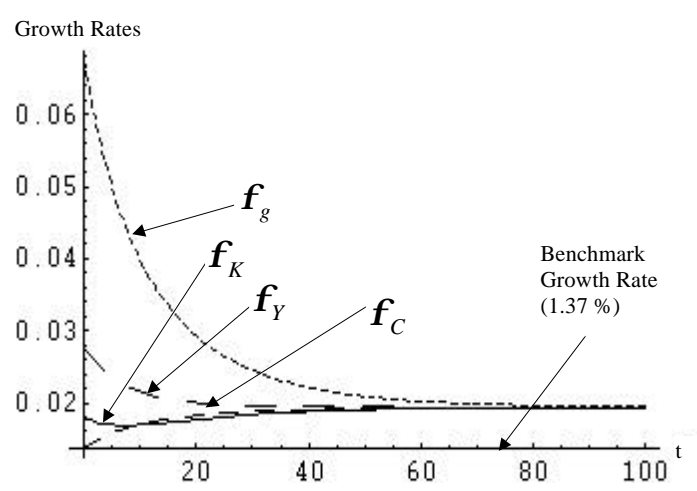

Figure 1.2. Growth Rates: $\phi_{K}, \phi_{g}, \phi_{C}, \phi_{Y}$

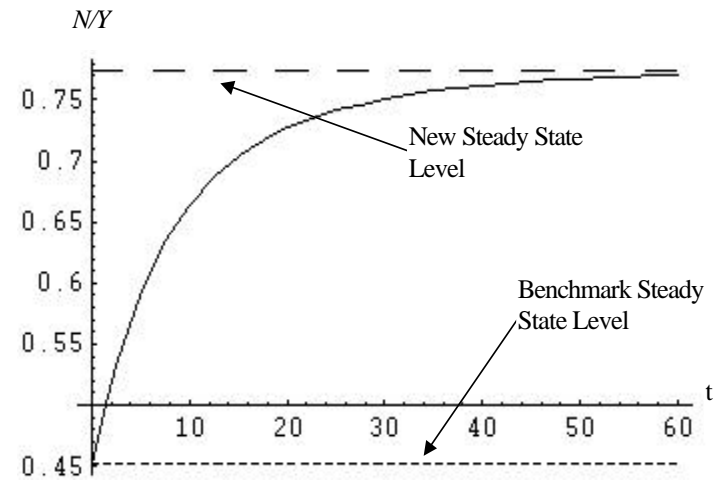

Figure 1.4. Debt-Output Ratio 
Figure 2: Comparison of Passive Response with Optimal Response

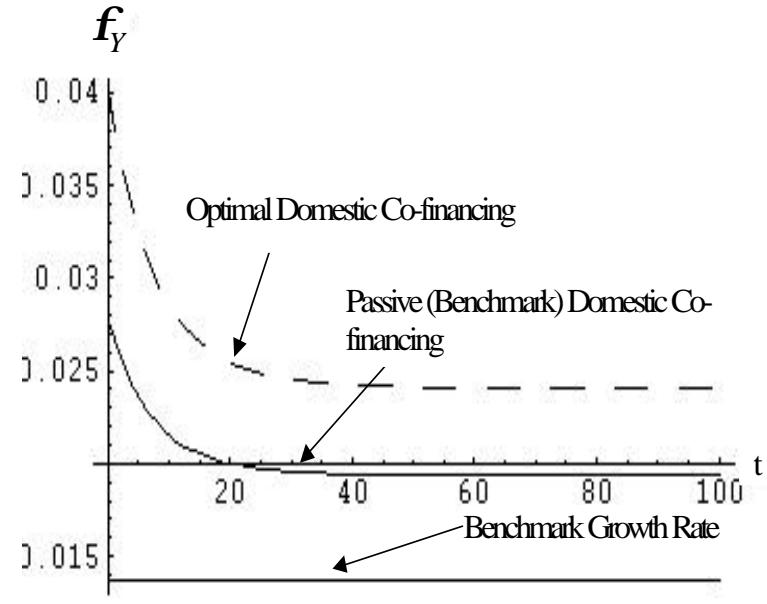

Figure 2.1. Output Growth Rates Under Different Regimes of Domestic Co-financing

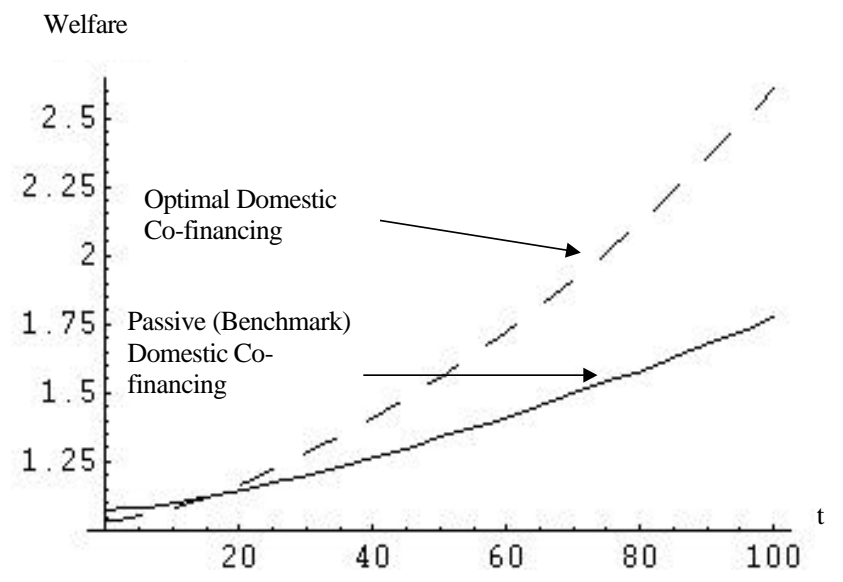

Figure 2.2. Welfare Paths Under Different Regimes of Domestic Co-financing 


\section{Figure 3. Transitional Adjustment to a Temporary Pure Transfer Shock}

$$
\lambda=0 ; \sigma=0.05 \text {; Duration of Shock }=10 \text { years }
$$

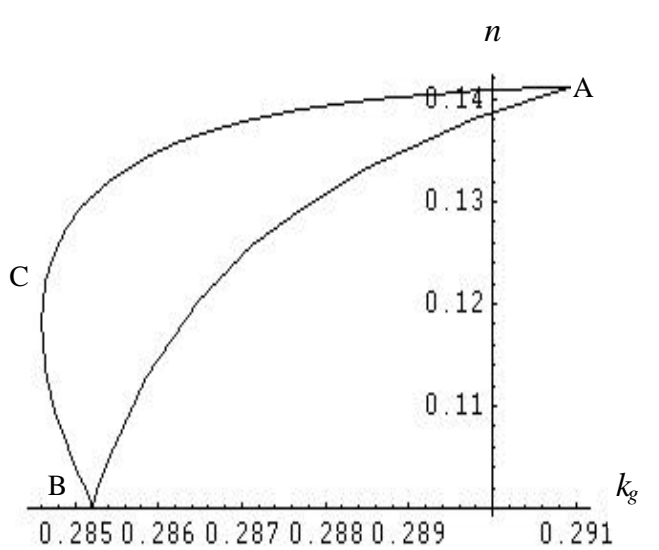

Figure 3.1. Transitional Adjustment Locus.

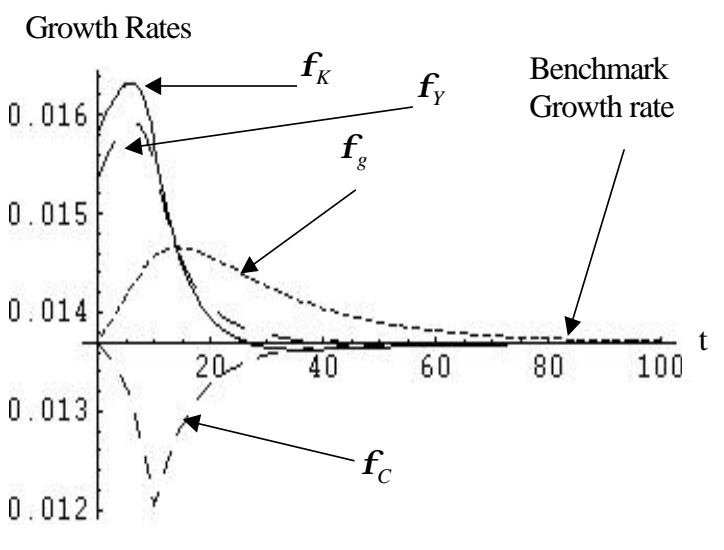

Figure 3.2. Growth Rates: $\phi_{K}, \phi_{g}, \phi_{C}, \phi_{Y}$.
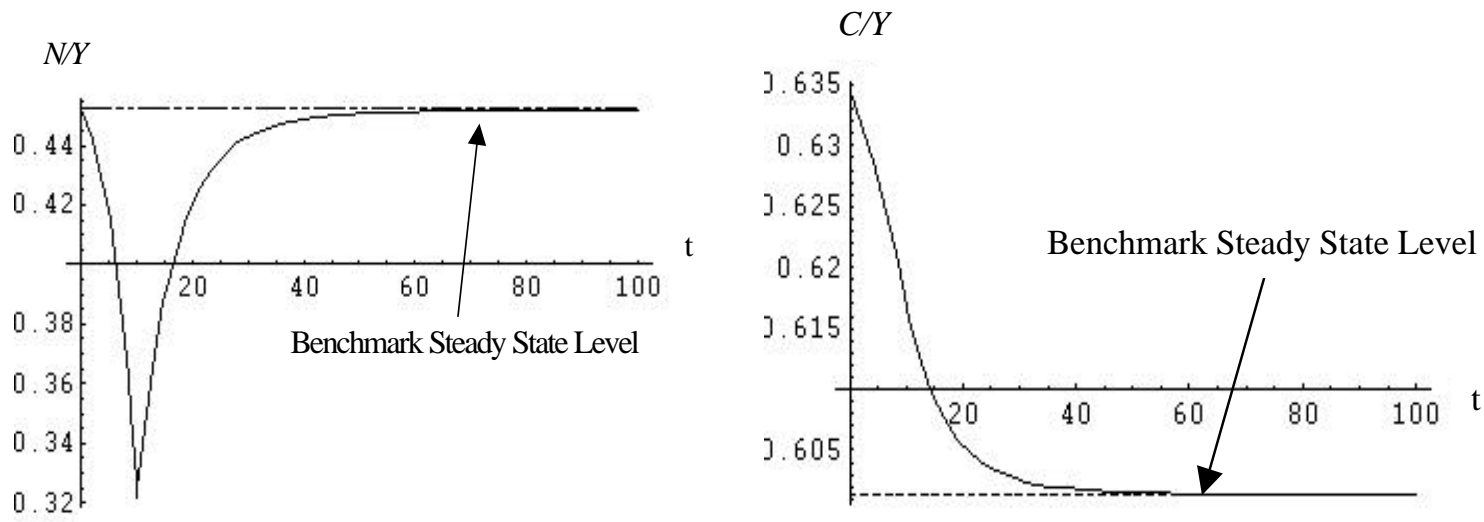

Figure 3.3. Debt-Output Ratio.

Figure 3.4. Consumption-Output Ratio.

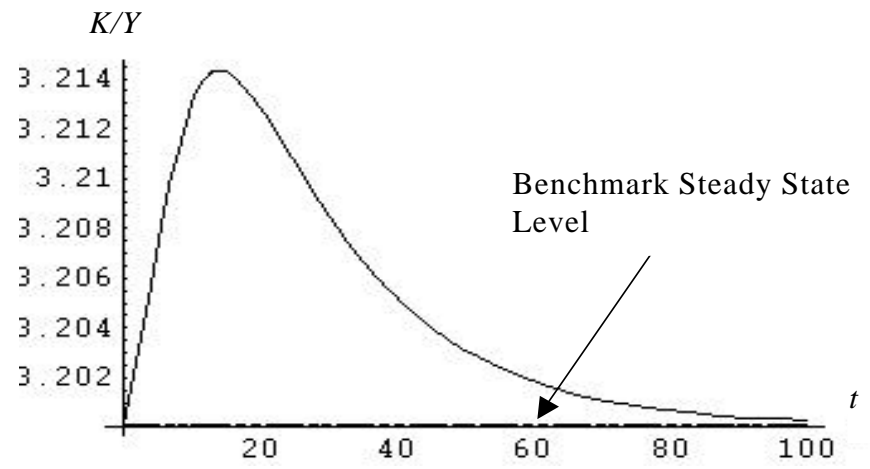

Figure 3.5. Capital-Output Ratio 
Figure 4. Transitional Adjustment to a Temporary Productive/Tied Transfer Shock $\lambda=1 ; \sigma=0.05$; Duration of Shock $=10$ years
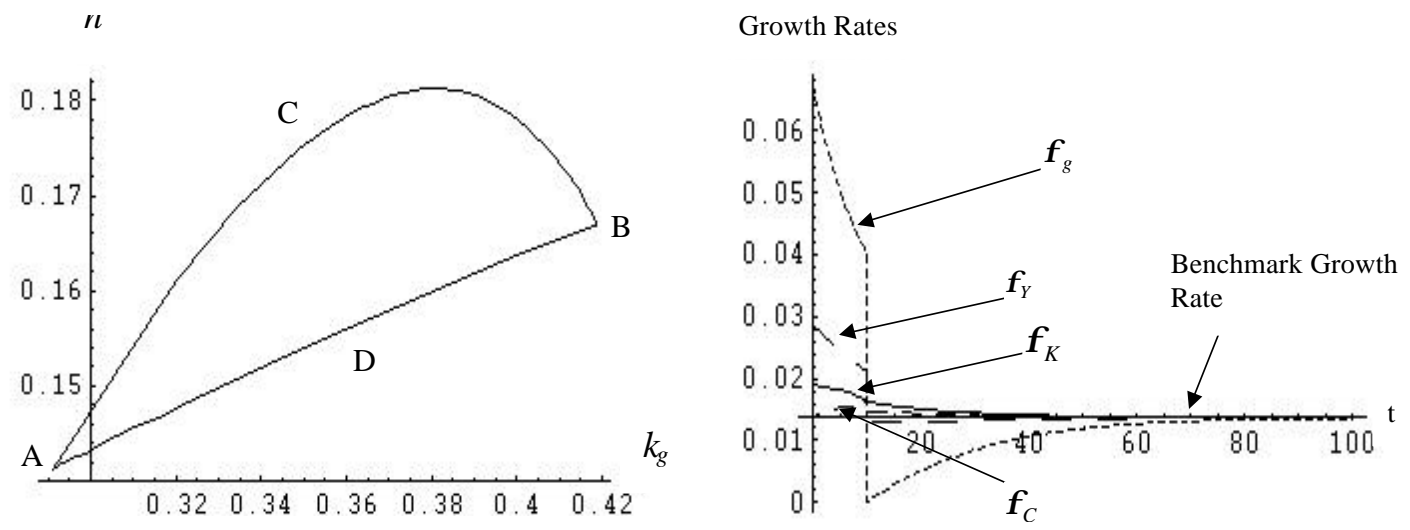

Figure 4.1. Transitional Adjustment Locus.

Figure 4.2. Growth Rates: $\phi_{K}, \phi_{g}, \phi_{C}, \phi_{Y}$

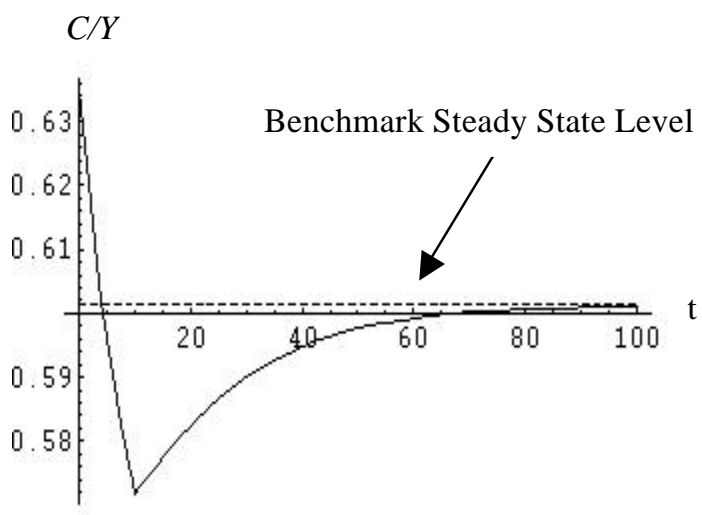

Figure 4.3. Consumption-Output Ratio.

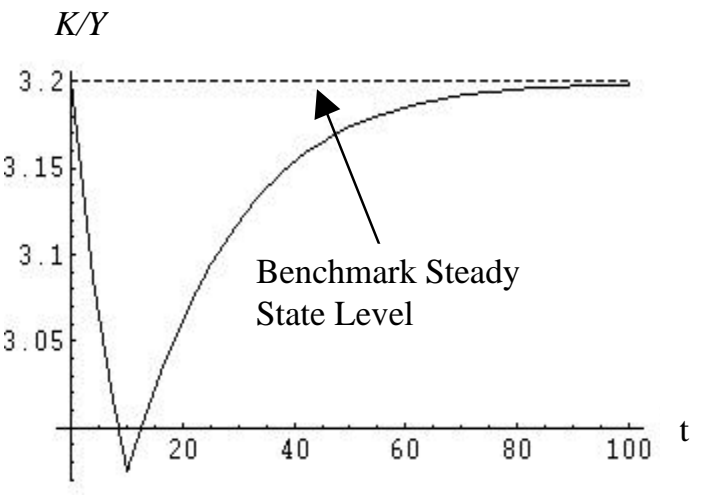

Figure 4.4. Capital-Output Ratio

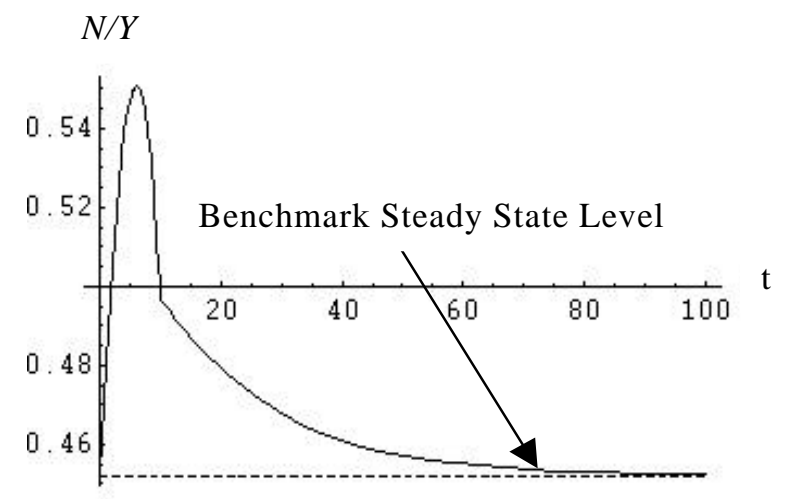

Figure 4.5. Debt-output Ratio. 


\section{Figure 5. A Comparative Analysis of the Permanent Effects of Temporary}

\section{Productive and Pure Transfer Shocks}

$($ Benchmark Levels $=1)$

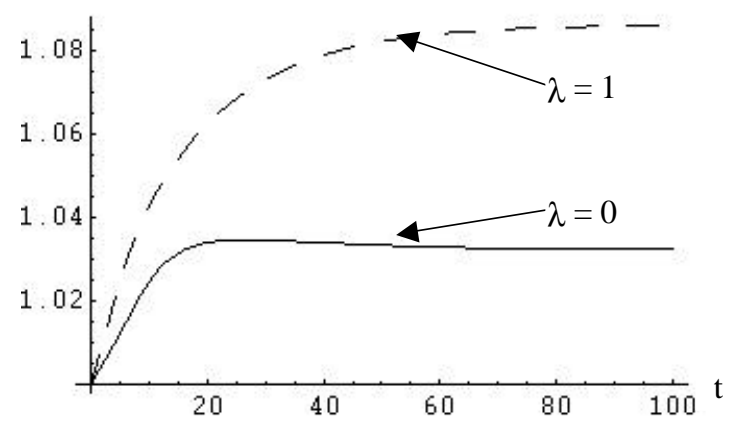

Figure 5.1. Change in Stock of Private Capital $(K)$ Relative to its Benchmark.

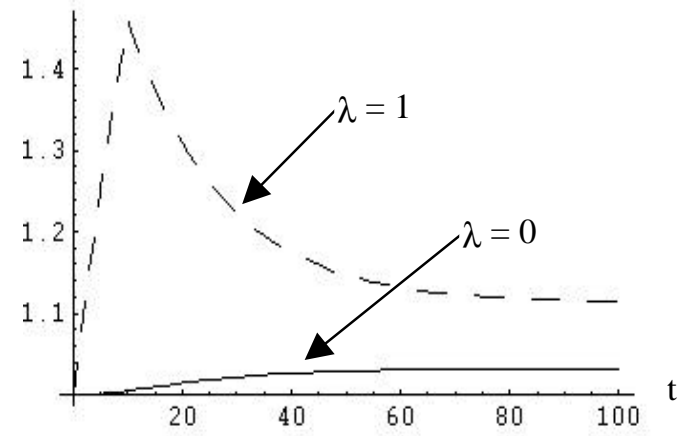

Figure 5.2. Change in Stock of Public Capital $\left(K_{g}\right)$ Relative to its Benchmark.

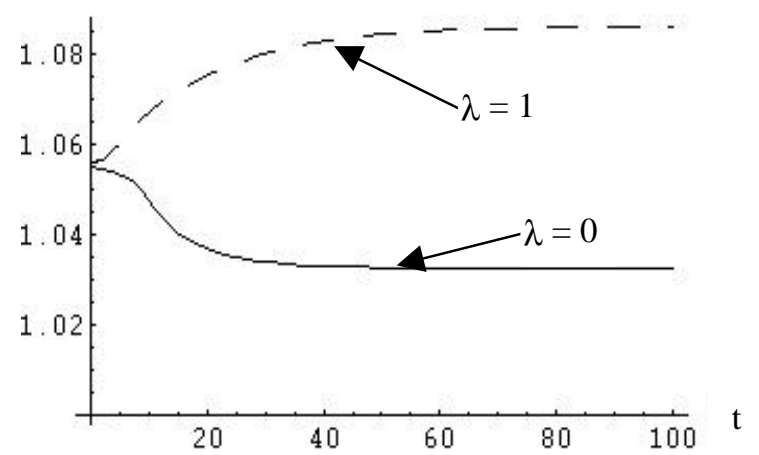

Figure 5.3. Change in Level of Consumption $(C)$ Relative to its Benchmark.

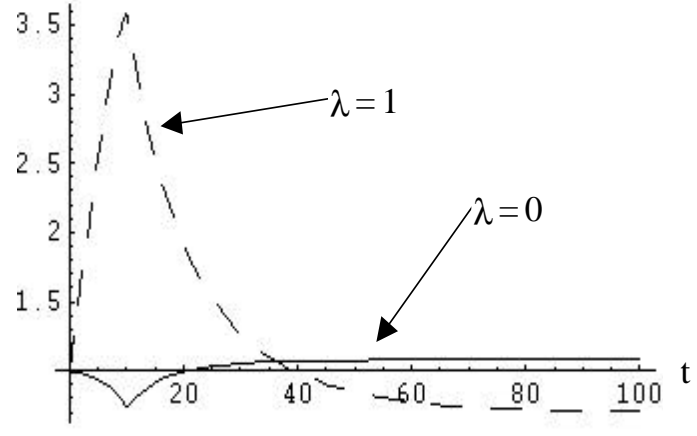

Figure 5.4. Change in Stock of Debt $(N)$ Relative to its Benchmark.

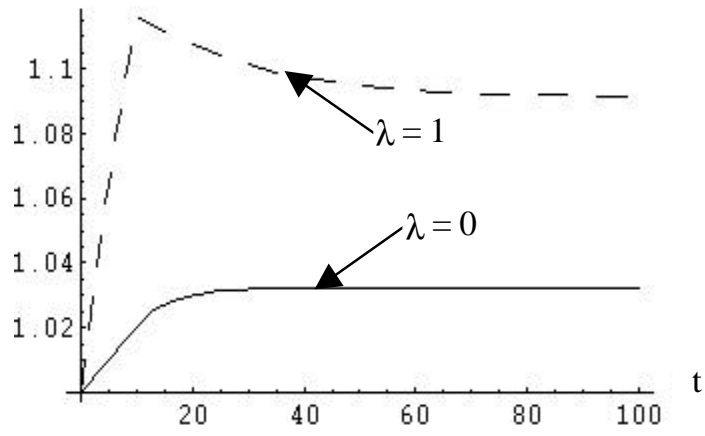

Figure 5.5. Change in Level of Output $(Y)$ Relative to its Benchmark.

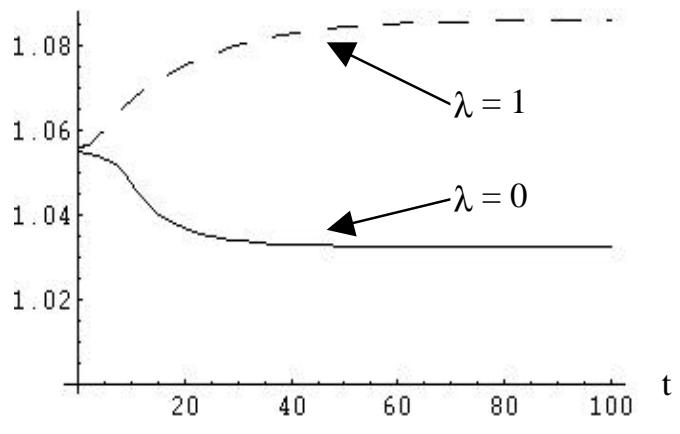

Figure 5.6. Change in Level of Welfare $(W)$ Relative to its Benchmark. 